\title{
The Exact Theoretical Rational Expectations Monetary Aggregate
}

\author{
by \\ William A. Barnett, \\ Washington University in St. Louis, \\ St. Louis, Missouri \\ Melvin J. Hinich \\ University of Texas at Austin, \\ Austin, Texas \\ and Piyu Yue, \\ $\mathrm{IC}^{2}$ Institute at the University of Texas at Austin \\ Austin, Texas
}

December 28, 1999

Barnett's research was partially supported by NSF grant SES 9223557. Address correspondence to : William A. Barnett, Department of Economics, Washington University, Campus Box 1208, One Brookings Drive, St. Louis, MO 63130-4889, USA; e-mail: barnett@wueconc.wustl.edu. 
Running Head:

Exact Theoretical Monetary Aggregate

Contact Author:

Mailing Address: William A. Barnett, Department of Economics, Campus Box 1208, One

Brookings Drive, St. Louis, Missouri 63130-4899

Phone: $314-935-4236$

Fax: $314-935-4156$

E-mail: barnett@wueconc.wustl.edu 


\section{Abstract:}

In aggregation theory, index numbers are judged relative to their ability to track the exact aggregator functions nested within the economy's structure. Within the monetary sector, Barnett, Liu, and Jensen (1997) compared two statistical index numbers: the Divisia monetary aggregate and the simple sum monetary aggregate. They produced those comparisons using simulated data. In this paper, we again compare those two statistical index numbers with the exact rational expectations monetary aggregate, but we use actual data. Since we are not using simulated data, we estimate the parameters of the Euler equations and thereby of the nested monetary aggregator function using generalized method of moments. We explore the tracking errors of the two index numbers relative to the estimated exact aggregate. We investigate the circumstances under which risk aversion increases tracking error. We also use polyspectral methods to test for the existence of remaining nonlinear structure in the residual tracking errors.

Keywords:

Monetary aggregation, index number theory, spectral analysis, nonlinearity 


\title{
The Exact Theoretical Rational Expectations Monetary Aggregate
}

\author{
by William A. Barnett, Melvin J. Hinich, and Piyu Yue
}

\section{Introduction}

In microeconomic aggregation theory, index numbers are judged relative to their ability to track the exact aggregator functions nested within the economy's structure. Relative to that criterion within the economy's monetary sector, Barnett, Liu, and Jensen (1997) compared two statistical index numbers: the Divisia monetary aggregate (with and without CCAPM adjustment for risk) and the simple sum monetary aggregate. Barnett, Liu, and Jensen (1997) produced those comparisons using simulated data at various settings of the parameters of an Euler equations model of monetary assets demand. In this paper, we similarly compare the two statistical index numbers with the exact rational expectations monetary aggregate, but we use actual data. Since we are not using simulated data, we need to estimate the parameters of the Euler equations and thereby of the nested monetary aggregator function. We do so using generalized method of moments. We then plot the time paths of the resulting estimated exact aggregate and the two approximating statistical index numbers.

We also compare the dynamic behavior of the two statistical index numbers with the dynamic behavior of the estimated exact aggregator function in the frequency domain using polyspectral methods. In particular, we investigate the ability of the two statistical indexes to extract the nonlinear structure from the estimated exact aggregate's time series. In addition to using Hinich's well know asymptotic bispectrum test, we bootstrap his test statistic to acquire a finite sample inference. The objective is to determine whether there exists any unexplained residual nonlinear structure in the tracking errors of the two statistical index numbers. 
This line of research in monetary economics began with Barnett (1980) in the perfect certainty case. A long list of published papers and books have been motivated by Barnett's original perfect certainty model, based upon consumer demand theory. While the applications of the perfect certainty approach are far more extensive than those of the recent extensions to a stochastic environment, there is in place a small but growing literature on Euler equation estimation of nested aggregator functions over monetary assets. That extended literature began with Poterba and Rotemberg (1987) and Barnett, Hinich, and Yue (1991) for consumer demand. Analogous research, in both the perfect certainty and risk cases, has recently been applied to manufacturing firms that demand monetary services and financial intermediaries that produce monetary services. A collection of many of the most important papers on this subject for all three categories of economic agents, with unifying discussion, can be found in Barnett and Serletis (2000). ${ }^{1}$

According to the "Barnett critique," as defined by Chrystal and MacDonald (1994, p. 76), an internal inconsistency exists between the microeconomics used to model private-sector structure and the aggregator functions implicitly used to produce the monetary aggregate data supplied by most central banks. This internal inconsistency can do considerable damage to inferences about private-sector behavior, when central bank monetary aggregate data are used. Chrystal and MacDonald (1994, p. 76) have observed the following regarding "the problems with tests of money in the economy in recent years ... Rather than a problem associated with the Lucas crituque, it could instead be a problem stemming from the "Barnett Critique."' In fact, Barnett-critique issues have been used to cast doubt upon many widely held views in monetary economics, as emphasized by Barnett, Fisher, and Serletis (1992), Belongia (1996), Chrystal and MacDonald (1994), and Barnett and Serletis (2000). Based upon this rapidly growing line of 
research, Chrystal and MacDonald (1994, p. 108) conclude---in our opinion correctly---that "rejections of the role of money based upon flawed money measures are themselves easy to reject."

In the current paper, we compare the behavior of the exact monetary aggregate with that of the statistical index number approximations under risk, but only for consumers. Comparable results for manufacturing firms and financial intermediaries already have been published in Barnett and Zhou (1994) and Barnett, Kirova, and Pasupathy (1995), but without frequency domain tests of successful extraction of nonlinear dynamics from the tracking errors. The data used in this paper are those supplied in Barnett, Hinich, and Yue (1991), to assure comparability with the results in that paper. In one case, we explore robustness to increased sample size, by extending the sample to include the most recently available data.

\section{Consumer Demand for Monetary Assets}

In this section we formulate a representative consumer's stochastic decision problem over consumer goods and monetary assets. The consumer's decisions are made in discrete time over a finite planning horizon for the time intervals, $t, t+1, \ldots, s, \ldots, t+T$, where $t$ is the current time period and $\mathrm{t}+\mathrm{T}$ is the terminal planning period. The variables used in defining the consumer's decision are as follows:

$\mathbf{x}_{\mathrm{S}}=\mathrm{n}$ dimensional vector of real consumption of goods and services during period $\mathrm{s}$, $\mathbf{p}_{\mathrm{s}}=\mathrm{n}$ dimensional vector of goods and services prices and of durable goods rental prices during period $\mathrm{s}$, 
$\mathbf{a}_{\mathrm{s}}=\mathrm{k}$ dimensional vector of real balances of monetary assets during

period s,

$\rho_{\mathrm{s}}=\mathrm{k}$ dimensional vector of nominal holding period yields of monetary assets,

$\mathrm{A}_{\mathrm{s}}=$ holdings of the benchmark asset during period $\mathrm{s}$,

$\mathrm{R}_{\mathrm{S}}=$ the one-period holding yield on the benchmark asset during period $\mathrm{s}$,

$I_{s}=$ the sum of all other sources of income during period $\mathrm{s}$,

$p_{\mathrm{s}}^{*}=p_{\mathrm{S}}^{*}\left(\mathbf{p}_{\mathrm{s}}\right)=$ the true cost of living index.

Define $\mathrm{Y}$ to be a compact subset of the $\mathrm{n}+\mathrm{k}+2$ dimensional nonnegative orthant. The consumer's consumption possibility set, $\mathrm{S}(\mathrm{s})$, for $\mathrm{s} \in\{\mathrm{t}, \ldots, \mathrm{t}+\mathrm{T}\}$ is:

$$
\begin{gathered}
\mathrm{S}(\mathrm{s})=\left\{\left(\mathbf{a}_{\mathrm{s}}, \mathbf{x}_{\mathrm{s}}, \mathrm{A}_{\mathrm{s}}\right) \in \mathrm{Y}: \sum_{i=1}^{n} p_{i s} x_{i s}=\right. \\
\left.+\sum_{\mathrm{i}=1}^{\mathrm{k}}\left[\left(1+\mathrm{\rho}_{\mathrm{i}, \mathrm{s}-1}\right) \mathrm{p}_{\mathrm{s}-1}^{*} \mathrm{a}_{\mathrm{i}, \mathrm{s}-1}-\mathrm{p}_{\mathrm{s}}^{*} \mathrm{a}_{\mathrm{is}}\right]+\left(1+\mathrm{R}_{\mathrm{s}-1}\right) \mathrm{p}_{\mathrm{s}-1}^{*} \mathrm{~A}_{\mathrm{s}-1}-\mathrm{p}_{\mathrm{s}}^{*} \mathrm{~A}_{\mathrm{s}}+\mathrm{I}_{\mathrm{s}}\right\}
\end{gathered}
$$

Under the assumption of rational expectations, the distribution of random variables is known to the consumer. Since current period interest rates are not paid until the end of the period, they may be contemporaneously unknown to the consumer. Nevertheless, observe that during period $t$ the only interest rates that enter into $S(t)$ are interest rates paid during period $t-1$, which are known at the start of period t. Similarly $\mathbf{p}_{\mathrm{t}}$ and $\mathrm{p}_{t}^{*}$ are determined and known to the consumer at the start of period t. Hence $\left(\mathbf{a}_{t}, \mathbf{x}_{t}, A_{t}\right)$ can be chosen deterministically in a manner that assures that $\left(\mathbf{a}_{\mathbf{t}}, \mathbf{x}_{t}, \mathrm{~A}_{\mathrm{t}}\right) \in \mathrm{S}(\mathrm{t})$ with certainty. However, that is not possible for $\mathrm{s}>\mathrm{t}$, since at the beginning of time period $t$, when the intertemporal decision is solved, the constraint sets $\mathrm{S}(\mathrm{s})$ for 
$s>t$ are random sets. Hence for $s>t$, the values of $\left(\mathbf{a}_{s}, \mathbf{x}_{s}, A_{s}\right)$ must be selected as stochastic process.

The benchmark asset $A_{S}$ provides no services other than its yield $R_{S}$. As a result, the benchmark asset does not enter the consumer's intertemporal utility function except in the last instant of the planning horizon. ${ }^{2}$ The asset is held only as a means of accumulating wealth to endow the next planning horizons. The consumer's intertemporal utility function is

$$
\mathrm{U}=\mathrm{U}\left(\mathbf{a}_{\mathrm{t}}, \ldots, \mathbf{a}_{\mathrm{s}}, \ldots, \mathbf{a}_{\mathrm{t}+\mathrm{T}} ; \mathbf{x}_{\mathbf{t}}, \ldots, \mathbf{x}_{\mathrm{S}}, \ldots, \mathbf{x}_{\mathrm{t}+\mathrm{T}} ; \mathrm{A}_{\mathrm{t}+\mathrm{T}}\right),
$$

where $\mathrm{U}$ is assumed to be intertemporally additively (strongly) separable, such that

$$
\begin{aligned}
& \mathrm{U}=\mathrm{u}\left(\mathbf{a}_{\mathrm{t}}, \mathbf{x}_{\mathrm{t}}\right)+\left(\frac{1}{1+\xi}\right) \mathrm{u}\left(\mathbf{a}_{\mathrm{t}+1}, \mathbf{x}_{\mathrm{t}+1}\right)+\ldots \\
& \ldots . .+\left(\frac{1}{1+\xi}\right)^{\mathrm{T}-1} \mathrm{u}\left(\mathbf{a}_{\mathrm{t}+\mathrm{T}-1}, \mathbf{x}_{\mathrm{t}+\mathrm{T}-1}\right)+\left(\frac{1}{1+\xi}\right)^{\mathrm{T}} \mathrm{u}\left(\mathbf{a}_{\mathrm{t}+\mathrm{T}}, \mathbf{x}_{\mathrm{t}+\mathrm{T}}, \mathrm{A}_{\mathrm{t}+\mathrm{T}}\right) \\
& =\sum_{\mathrm{s}=\mathrm{t}}^{\mathrm{t}+\mathrm{T}-1}\left(\frac{1}{1+\xi}\right)^{\mathrm{s}-\mathrm{t}} \mathrm{u}\left(\mathbf{a}_{\mathrm{s}}, \mathbf{x}_{\mathrm{s}}\right)+\left(\frac{1}{1+\xi}\right)^{\mathrm{T}} \mathrm{u}_{\mathrm{T}}\left(\mathbf{a}_{\mathrm{t}+\mathrm{T}}, \mathbf{x}_{\mathrm{t}+\mathrm{T}}, \mathrm{A}_{\mathrm{t}+\mathrm{T}}\right),
\end{aligned}
$$

and the consumer's subjective rate of time preference, $\xi$, is assumed to be constant. ${ }^{3}$ The single period utility functions, $\mathrm{u}$ and $\mathrm{u}_{\mathrm{T}}$, are assumed to be increasing and strictly quasiconcave.

Given the price and interest rate processes, the consumer selects the deterministic point $\left(\mathbf{a}_{t}, \mathbf{x}_{t}, A_{t}\right)$ and the stochastic processes $\left(\mathbf{a}_{\mathrm{s}}, \mathbf{x}_{\mathrm{s}}, \mathrm{A}_{\mathrm{s}}\right), \mathrm{s}=\mathrm{t}+1, \ldots, \mathrm{t}+\mathrm{T}$, to maximize the expected value of $\mathrm{U}$ over the planning horizon, subject to the sequence of choice set constraints. Formally, the consumer's decision problem is the following.

Problem 1: Choose the deterministic point $\left(\mathbf{a}_{t}, \mathbf{x}_{t}, A_{t}\right)$ and the stochastic process $\left(\mathbf{a}_{s}, \mathbf{x}_{\mathrm{s}}, \mathrm{A}_{\mathrm{s}}\right), \mathrm{s}=$ $\mathrm{t}+1, \ldots, \mathrm{t}+\mathrm{T}$, to maximize 


$$
\mathrm{u}\left(\mathbf{a}_{\mathrm{t}}, \mathbf{x}_{\mathrm{t}}\right)+\mathrm{E}_{\mathrm{t}}\left[\sum_{\mathrm{s}=\mathrm{t}+1}^{\mathrm{t}+\mathrm{T}-1}\left(\frac{1}{1+\xi}\right)^{\mathrm{s}-\mathrm{t}} \mathrm{u}\left(\mathbf{a}_{\mathrm{s}}, \mathbf{x}_{\mathrm{s}}\right)+\left(\frac{1}{1+\xi}\right)^{\mathrm{T}} \mathrm{u}_{\mathrm{T}}\left(\mathbf{a}_{\mathrm{t}+\mathrm{T}}, \mathbf{x}_{\mathrm{t}+\mathrm{T}}, \mathrm{A}_{\mathrm{t}+\mathrm{T}}\right)\right]
$$

subject to $\left(\mathbf{a}_{\mathrm{s}}, \mathbf{x}_{\mathrm{s}}, \mathrm{A}_{\mathrm{s}}\right) \in \mathrm{S}(\mathrm{s})$ for $\mathrm{s}=\mathrm{t}, \ldots, \mathrm{t}+\mathrm{T}$.

We use $\mathrm{E}_{\mathrm{t}}$ to designate the expectations operator conditionally upon the information that exists at time t.

In the infinite planning horizon case, the decision problem becomes:

Problem 2: Choose the deterministic point $\left(\mathbf{a}_{t}, \mathbf{x}_{t}, A_{t}\right)$ and the stochastic process $\left(\mathbf{a}_{\mathrm{s}}, \mathbf{x}_{\mathrm{s}}, \mathrm{A}_{\mathrm{s}}\right), s=t+1, \ldots, \infty$, to maximize

$$
\mathrm{u}\left(\mathbf{a}_{\mathrm{t}}, \mathbf{x}_{\mathrm{t}}\right)+\mathrm{E}_{\mathrm{t}}\left[\sum_{s=t+1}^{\infty}\left(\frac{1}{1+\xi}\right)^{\mathrm{s}-\mathrm{t}} \mathrm{u}\left(\mathbf{a}_{\mathrm{s}}, \mathbf{x}_{\mathrm{s}}\right)\right]
$$

subject to $\left(\mathbf{a}_{\mathrm{s}}, \mathbf{x}_{\mathrm{s}}, \mathrm{A}_{\mathrm{s}}\right) \in \mathrm{S}(\mathrm{s})$ for $\mathrm{s} \geq \mathrm{t}$, and also subject to

$$
\mathrm{E}_{\mathrm{t}}\left(\frac{1}{1+\xi}\right)^{\mathrm{s}-\mathrm{t}} \mathrm{A}_{\mathrm{s}} \underset{s \rightarrow \infty}{\longrightarrow} 0 .
$$

The latter constraint rules out perpetual borrowing at the benchmark rate of return, $\mathrm{R}_{\mathrm{t}}$.

\section{Existence of a Monetary Aggregate for the Consumer}

In order to assure the existence of a monetary aggregate for the consumer, we partition the vector of monetary asset quantities, $\mathbf{a}_{\mathrm{s}}$, such that $\mathbf{a}_{\mathrm{s}}=\left(\mathbf{m}_{\mathrm{s}}, \mathbf{h}_{\mathrm{s}}\right)$. We correspondingly partition the vector of interest rates of those assets, $\boldsymbol{\rho}_{\mathrm{s}}$, such that $\boldsymbol{\rho}_{\mathrm{s}}=\left(\mathbf{r}_{\mathrm{s}}, \mathbf{i}_{\mathrm{S}}\right)$. We then assume that the utility function, $\mathrm{u}$, is blockwise weakly separable in $\mathbf{m}_{\mathrm{s}}$ and in $\mathbf{x}_{\mathrm{S}}$ for some such partition of $\mathbf{a}_{\mathrm{s}}$. Hence there exists a monetary aggregator ("category utility") function, M, and consumer goods 
aggregator function, $\mathrm{X}$, and a utility function, $\mathrm{u}^{*}$, such that

$$
\mathrm{u}\left(\mathbf{a}_{\mathrm{s}}, \mathbf{x}_{\mathrm{S}}\right)=\mathrm{u} *\left(\mathrm{M}\left(\mathbf{m}_{\mathrm{S}}\right), \mathbf{h}_{\mathrm{s}}, \mathrm{X}\left(\mathbf{x}_{\mathrm{S}}\right)\right)
$$

We assume that the terminal period utility function in the finite planning horizon case is

correspondingly weakly separable, such that $\mathrm{u}_{\mathrm{T}}\left(\mathbf{a}_{\mathrm{S}}, \mathbf{x}_{\mathrm{S}}, \mathrm{A}_{\mathrm{S}}\right)=\mathrm{u}_{\mathrm{T}}^{*}\left(\mathrm{M}\left(\mathbf{m}_{\mathrm{S}}\right), \mathbf{h}_{\mathrm{S}}, \mathrm{X}\left(\mathbf{x}_{\mathrm{S}}\right), \mathrm{A}_{\mathrm{S}}\right)$.

Then it follows that the exact monetary aggregate, measuring the welfare acquired from consuming the services of $\mathbf{m}_{\mathrm{s}}$, is

$$
\mathrm{M}_{\mathrm{s}}=\mathrm{M}\left(\mathbf{m}_{\mathrm{S}}\right)
$$

We define the dimension of $\mathbf{m}_{\mathrm{s}}$ to be $\mathrm{k}_{1}$, and the dimension of $\mathbf{h}_{\mathrm{s}}$ to be $\mathrm{k}_{2}$, so that $\mathrm{k}=\mathrm{k}_{1}+\mathrm{k}_{2}$.

It is clear that equation 6 does define the exact monetary aggregate in the welfare sense, since $\mathrm{M}_{\mathrm{S}}$ measures the consumer's subjective evaluation of the services that he receives from holding $\mathbf{m}_{\mathrm{s}}$. However it also can be shown that equation 6 defines the exact monetary aggregate in the aggregation theoretic sense. In particular, the stochastic process $M_{s}, s \geq t$, contains all of the information about $\mathbf{m}_{\mathrm{s}}$ that is needed by the consumer to solve the rest of his decision problem. This conclusion is based upon the following theorem, which we call the consumer's aggregation theorem.

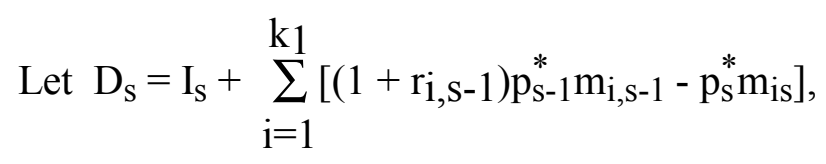

and let

$$
\begin{aligned}
\Delta(\mathrm{s}) & =\left\{\left(\mathbf{h}_{\mathrm{s}}, \mathbf{x}_{\mathrm{s}}, \mathrm{A}_{\mathrm{s}}\right) \in \mathrm{Y}: \sum_{i=1}^{n} p_{i s} x_{i s}=\right. \\
& \left.+\sum_{\mathrm{i}=1}^{\mathrm{k}_{2}}\left[\left(1+\mathbf{i}_{\mathrm{i}, \mathrm{s}-1}\right) \mathrm{p}_{\mathrm{s}-1}^{*} \mathrm{~h}_{\mathrm{i}, \mathrm{s}-1}-\mathrm{p}_{\mathrm{s}}^{*} \mathrm{~h}_{\mathrm{is}}\right]+\left(1+\mathrm{R}_{\mathrm{s}-1}\right) \mathrm{p}_{\mathrm{s}-1}^{*} \mathrm{~A}_{\mathrm{s}-1}-\mathrm{p}_{\mathrm{s}}^{*} \mathrm{~A}_{\mathrm{s}}+\mathrm{D}_{\mathrm{s}}\right\} .
\end{aligned}
$$


Let the deterministic point $\left(\mathbf{a}_{\mathrm{t}}^{*}, \mathbf{x}_{\mathrm{t}}^{*}, \mathrm{~A}_{\mathrm{t}}^{*}\right)$ and the stochastic process $\left(\mathbf{a}_{\mathrm{s}}^{*}, \mathbf{x}_{\mathrm{s}}^{*}, \mathrm{~A}_{\mathrm{s}}^{*}\right), \mathrm{s} \geq \mathrm{t}+1$, solve problem 1 (or problem 2, if $\mathrm{T}=\infty$ ). Consider the following decision problems, which are conditional upon prior knowledge of the aggregate process $\mathrm{M}_{\mathrm{S}}^{*}=\mathrm{M}\left(\mathbf{m}_{\mathrm{S}}^{*}\right)$, although not upon the component processes $\mathbf{m}_{\mathrm{s}}^{*}$.

Problem 1a: : Choose the deterministic point $\left(\mathbf{h}_{t}, \mathbf{x}_{t}, A_{t}\right)$ and the stochastic process $\left(\mathbf{h}_{\mathrm{s}}, \mathbf{x}_{\mathrm{s}}, \mathrm{A}_{\mathrm{s}}\right)$, $\mathrm{s}=\mathrm{t}+1, \ldots, \mathrm{t}+\mathrm{T}$, to maximize

$$
\begin{aligned}
& \mathrm{u}^{*}\left(\mathrm{M}_{\mathrm{t}}^{*}, \mathbf{h}_{\mathrm{t}}, \mathbf{x}_{\mathrm{t}}\right) \\
& +\mathrm{E}_{\mathrm{t}}\left[\sum_{\mathrm{s}=\mathrm{t}+1}^{\mathrm{t}+\mathrm{T}-1}\left(\frac{1}{1+\xi}\right)^{\mathrm{s}-\mathrm{t}} \mathrm{u}^{*}\left(\mathrm{M}_{\mathrm{s}}^{*}, \mathbf{h}_{\mathrm{s}}, \mathbf{x}_{\mathrm{s}}\right)+\left(\frac{1}{1+\xi}\right)^{\mathrm{T}} \mathrm{u}_{\mathrm{T}}^{*}\left(\mathrm{M}_{\mathrm{T}}^{*}, \mathbf{h}_{\mathrm{s}}, \mathbf{x}_{\mathrm{s}}, \mathrm{A}_{\mathrm{s}}\right)\right]
\end{aligned}
$$

subject to $\left(\mathbf{h}_{\mathrm{s}}, \mathbf{x}_{\mathrm{s}}, \mathrm{A}_{\mathrm{s}}\right) \in \Delta(\mathrm{s})$ for $\mathrm{s}=\mathrm{t}, \ldots, \mathrm{t}+\mathrm{T}$, with the process $\mathrm{M}_{\mathrm{s}}^{*}$ given for $\mathrm{s} \geq \mathrm{t}$.

Problem 2a: Choose the deterministic point $\left(\mathbf{h}_{t}, \mathbf{x}_{t}, A_{t}\right)$ and the stochastic process $\left(\mathbf{h}_{\mathrm{s}}, \mathbf{x}_{\mathrm{s}}, \mathrm{A}_{\mathrm{s}}\right)$, $s=t+1, \ldots, \infty$, to maximize

$$
\mathrm{u}^{*}\left(\mathrm{M}_{\mathrm{t}}^{*}, \mathbf{h}_{\mathrm{t}}, \mathbf{x}_{\mathrm{t}}\right)+\mathrm{E}_{\mathrm{t}}\left[\sum_{s=t+1}^{\infty}\left(\frac{1}{1+\xi}\right)^{\mathrm{s}-\mathrm{t}} \mathrm{u}^{*}\left(\mathrm{M}_{\mathrm{s}}^{*}, \mathbf{h}_{\mathrm{s}}, \mathbf{x}_{\mathrm{s}}\right)\right]
$$

subject to $\left(\mathbf{h}_{\mathrm{s}}, \mathbf{x}_{\mathrm{s}}, \mathrm{A}_{\mathrm{s}}\right) \in \Delta(\mathrm{s})$ for $\mathrm{s} \geq \mathrm{t}$, and also subject to

$$
\mathrm{E}_{\mathrm{t}}\left(\frac{1}{1+\xi}\right)^{\mathrm{s}-\mathrm{t}} \mathrm{A}_{\mathrm{s}} \underset{s \rightarrow \infty}{\longrightarrow} 0
$$

with the process $\mathrm{M}_{\mathrm{s}}^{*}$ given for $\mathrm{s} \geq \mathrm{t}$. 
Theorem 1 (Consumer's Aggregation Theorem): Let the deterministic point $\left(\mathbf{m}_{\mathrm{t}}, \mathbf{h}_{\mathrm{t}}, \mathbf{x}_{\mathrm{t}}, \mathrm{A}_{\mathrm{t}}\right)$ and the stochastic process $\left(\mathbf{m}_{\mathrm{s}}, \mathbf{h}_{\mathrm{s}}, \mathbf{x}_{\mathrm{s}}, \mathrm{A}_{\mathrm{s}}\right), \mathrm{s}=\mathrm{t}+1, \ldots, \mathrm{t}+\mathrm{T}$, solve problem 1 . Then the deterministic point $\left(\mathbf{h}_{t}, \mathbf{x}_{t}, A_{t}\right)$ and the stochastic process $\left(\mathbf{h}_{\mathrm{s}}, \mathbf{x}_{\mathrm{s}}, \mathrm{A}_{\mathrm{s}}\right), \mathrm{s}=\mathrm{t}+1, \ldots, \mathrm{t}+\mathrm{T}$, will solve problem 1a conditionally upon $\mathrm{M}_{\mathrm{s}}^{*}=\mathrm{M}\left(\mathbf{m}_{\mathrm{s}}\right)$ for $\mathrm{s}=\mathrm{t}, \ldots, \mathrm{t}+\mathrm{T}$. Similarly let the deterministic point $\left(\mathbf{m}_{t}, \mathbf{h}_{t}, \mathbf{x}_{t}, A_{t}\right)$ and the stochastic process $\left(\mathbf{m}_{\mathrm{s}}, \mathbf{h}_{\mathrm{s}}, \mathbf{x}_{\mathrm{s}}, \mathrm{A}_{\mathrm{s}}\right), \mathrm{s} \geq \mathrm{t}+1$ solve problem 2 . Then the deterministic point $\left(\mathbf{h}_{t}, \mathbf{x}_{t}, A_{t}\right)$ and the stochastic process $\left(\mathbf{h}_{s}, \mathbf{x}_{s}, A_{s}\right), s \geq t+1$ will solve problem 2a conditionally upon $\mathrm{M}_{\mathrm{s}}^{*}=\mathrm{M}\left(\mathbf{m}_{\mathrm{s}}\right)$ for $\mathrm{s} \geq \mathrm{t}$.

Clearly this aggregation theorem, proved in the appendix of Barnett, Liu, and Jensen (1997), applies not only when $M_{S}$ is produced by voluntary behavior, but also when the $M_{S}$ process is exogenously imposed upon the consumer, as through a perfectly inelastic supply function for $\mathrm{M}_{\mathrm{S}}$, set by central bank policy. In that case, problems 1a and 2a describe optimal behavior by the consumer in the remaining variables. Since $\left(\mathbf{h}_{\mathrm{S}}, \mathbf{x}_{\mathrm{S}}, \mathrm{A}_{\mathrm{s}}\right)$ are not assumed to be weakly separable from $M_{S}$, the information about $M_{S}$ is needed in the solution of problems 1a and 2a for the processes $\left(\mathbf{h}_{\mathrm{s}}, \mathbf{x}_{\mathrm{s}}, \mathrm{A}_{\mathrm{s}}\right)$. For example, the marginal rate of substitution between labor and goods may depend upon the value of $\mathrm{M}_{\mathrm{s}}$. Alternatively information about the simple sum aggregate over the components of $\mathbf{m}_{\mathrm{s}}$ is of no use in solving either problem 1a or 2a unless the monetary aggregator function $\mathrm{M}$ happens to be a simple sum. In other words, the simple sum aggregate contains useful information about behavior only if the components of $\mathbf{m}_{\mathrm{S}}$ are perfect substitutes in identical ratios (linear aggregation with equal coefficients).

\section{The Solution Procedure}

Using Bellman's principle, we can derive the first order conditions for solving Problems 1 and 2. Under the somewhat more restrictive conditions assumed by Poterba and Rotemberg 
(1987), the first order conditions derived below reduce to those acquired by Poterba and Rotemberg.

We concentrate on the infinite planning horizon problem 2, rather than on the finite planning horizon problem 2, since the contingency plan functions ("feedback rules") that solve problem 1 are time dependent in the finite planning horizon case, but not in the infinite planning horizon case. In the infinite planning horizon case, time enters only through the variables that enter those equations as arguments, rather than through time shifting of the functions themselves.

We begin by solving the budget constraint in equation (1) for the quantity of an arbitrary consumer good, $\mathrm{x}_{\mathrm{j}}$, and we then use the resulting rearranged constraint to eliminate $\mathrm{x}_{\mathrm{js}}$ from the intertemporal utility function in problem 2 for all $\mathrm{s} \geq \mathrm{t}$. For notational simplicity, we let $\mathbf{j}=1$. Let $\mathbf{z}_{1 \mathrm{~s}}=\left(\mathbf{a}_{\mathrm{s}}, \mathrm{A}_{\mathrm{s}}\right)$. To apply Bellman's method, we must define the control and state variables. Define the control variables during period $\mathrm{s}$ to be $\mathbf{z}_{\mathrm{s}}=\left(\mathbf{z}_{1 \mathrm{~s}}, \mathrm{x}_{2 \mathrm{~s}}, \ldots, \mathrm{x}_{\mathrm{ns}}\right)$. We define the state variables during period $\mathrm{s}$ to be $\left(\boldsymbol{B}_{1 \mathrm{~s}}, \boldsymbol{\emptyset}_{\mathrm{s}}\right)$, where the price and income state variables are $\boldsymbol{\sigma}_{\mathrm{s}}=\left(\left(\mathrm{p}_{2 \mathrm{~s}}, \ldots, \mathrm{p}_{\mathrm{ns}}\right), \mathrm{p}_{\mathrm{s}}^{*}, \mathrm{p}_{\mathrm{s}-1}{ }^{*}, \mathrm{R}_{\mathrm{s}-1}, \boldsymbol{\rho}_{\mathrm{s}-1}, \mathrm{I}_{\mathrm{s}}\right) / \mathrm{p}_{1 \mathrm{~s}}$, and where $\boldsymbol{\beta}_{1 \mathrm{~s}}=\left(\mathbf{a}_{\mathrm{s}-1}, \mathrm{~A}_{\mathrm{s}-1}\right)$.

Having eliminated the budget constraint by substitution as described above, problem 2 can be rewritten as follows:

Problem 2b: $:$ Choose the deterministic point $\mathbf{z}_{\mathfrak{t}}$ and the stochastic process $\mathbf{z}_{\mathrm{s}}, s=t+1, \ldots, \infty$, to maximize

$$
\mathrm{u}\left(\mathbf{z}_{\mathrm{t}}, \mathbf{\beta}_{\mathrm{t}}\right)+\mathrm{E}_{\mathrm{t}}\left[\sum_{s=t+1}^{\infty}\left(\frac{1}{1+\xi}\right)^{\mathrm{s}-\mathrm{t}} \mathrm{u}\left(\mathbf{z}_{\mathrm{s}}, \boldsymbol{\beta}_{\mathrm{S}}\right)\right]
$$

subject to 


$$
\mathbf{B}_{1, \mathrm{~s}+1}=\mathbf{z}_{1 \mathrm{~s}}
$$

and

$$
\mathrm{E}_{\mathrm{t}}\left(\frac{1}{1+\xi}\right)^{\mathrm{s}-\mathrm{t}} \mathrm{A}_{\mathrm{s}} \underset{s \rightarrow \infty}{\longrightarrow} 0
$$

with $\mathbf{B}_{\mathrm{t}}$ given.

Equations (11) are the transition equations, $\mathbf{B}_{\mathrm{S}+1}=\mathbf{g}\left(\mathbf{z}_{\mathrm{S}}, \mathbf{B}_{\mathrm{S}}\right)$, providing the evolution of future state variables as functions of the controls and the current state. We assume that the $\boldsymbol{\sigma}_{\mathrm{S}}$ process is Markovian. Applying the Benveniste and Scheinkman equations, we can acquire the Euler equations for the control variables.

The Euler equations which will be of the most use to us below are those for monetary assets. Replacing $\mathrm{X}\left(\mathbf{x}_{\mathrm{t}}\right)$ by $\mathrm{c}_{\mathrm{t}}$ in $\mathrm{u}$, those Euler equations become:

$$
E_{t}\left[\frac{\partial u}{\partial m_{i t}}-\rho \frac{p_{t}^{*}\left(R_{t}-r_{i t}\right)}{p_{t+1}^{*}} \frac{\partial u}{\partial c_{t+1}}\right]=0
$$

for $\mathrm{i}=1, \ldots, \mathrm{k}_{1}$, where $\mathrm{c}_{\mathrm{t}}=\mathrm{X}\left(\mathbf{x}_{\mathrm{t}}\right)$ is the exact quantity aggregate over $\mathbf{x}_{\mathrm{t}}$ and $\mathrm{p}_{\mathrm{t}}^{*}$ is its dual exact price aggregate. ${ }^{4}$ Similarly we can acquire the Euler equation for the consumer goods aggregate $c_{t}$, rather than for each of its components. The resulting Euler equation for $c_{t}$ is

$$
E_{t}\left[\frac{\partial u}{\partial c_{t}}-\rho \frac{p_{t}^{*}\left(1+R_{t}\right)}{p_{t+1}^{*}} \frac{\partial u}{\partial c_{t+1}}\right]=0
$$

\section{Monetary Policy}


Having the Bellman solution at hand, we are in a position to give further consideration to the policy implications of monetary aggregation through the Theoretical aggregate. Hence we now return to Theorem 1 and Problem 2a. Clearly the Bellman equation for Problem 2a can be written in a form analogous to that of the Bellman equation produced by Problem 2. The only changes are that the controls now are $\left(\mathbf{h}_{\mathrm{s}}, \mathrm{x}_{2 \mathrm{~s}}, \ldots, \mathrm{x}_{\mathrm{ns}}, \mathrm{A}_{\mathrm{s}}\right), \mathrm{s}=\mathrm{t}, \ldots, \infty$, while the state variables are $\left(\mathbf{h}_{\mathrm{s}-1}, \mathrm{~A}_{\mathrm{s}-1}, \boldsymbol{\sigma}_{\mathrm{S}}, \mathrm{M}_{\mathrm{S}}^{*}\right)$, where $\boldsymbol{\sigma}_{\mathrm{s}}$ is the vector of price and income state variables defined earlier. Hence the solution contingency plans solving problem $2 \mathrm{a}$ are of the form:

$$
\left(\mathbf{h}_{\mathrm{s}}, \mathrm{x}_{2 \mathrm{~s}}, \ldots, \mathrm{x}_{\mathrm{ns}}, \mathrm{A}_{\mathrm{s}}\right)=\mathbf{f}\left(\mathbf{h}_{\mathrm{s}-1}, \mathrm{~A}_{\mathrm{s}-1}, \mathbf{\omega}_{\mathrm{s}}, \mathrm{M}_{\mathrm{s}}^{*}\right)
$$

where all of the controls and state variables are deterministic for $\mathrm{s}=\mathrm{t}$.

The appearance of $M_{S}^{*}$ as a state variable has interesting policy implications. Clearly if $\mathrm{M}_{\mathrm{S}}^{*}$ is used as an indicator in the conduct of monetary policy, the monetary aggregate will indeed contain information about $\left(\mathbf{h}_{\mathrm{s}}, \mathrm{x}_{2 \mathrm{~s}}, \ldots, \mathrm{x}_{\mathrm{ns}}, \mathrm{A}_{\mathrm{s}}\right)$ and thereby about the final targets of monetary policy both in goods and labor markets. Alternatively suppose that policy instruments, such as the monetary base, are used to target the equilibrium path of $\mathrm{M}_{\mathrm{s}}^{*}$ as an intermediate target of policy. Assuming that the instruments are used in a manner that is not time inconsistent, as for example through an open loop policy, the equilibrium stochastic process for $\mathrm{M}_{\mathrm{S}}^{*}$ can be influenced by policy. Under our assumption of rational expectations, economic agents will know about the policy rule and hence about the targeted equilibrium process for $\mathrm{M}_{\mathrm{s}}^{*}$. The consumer then can solve problem $2 \mathrm{a}$ to acquire the optimal solution for the remaining variables conditionally upon the targeted process for $\mathrm{M}_{\mathrm{s}}^{*}$. 
We see that only $M_{S}^{*}$ can play these roles, if policy operates through a monetary target or indicator. The simple sum aggregate, which does not appear as a control in $\mathbf{f}$, can serve neither role. In fact the only information from the monetary asset portfolio, $\mathbf{m}_{\mathrm{s}}^{*}$, that is useful in solving problem $2 \mathrm{a}$ is $\mathrm{M}_{\mathrm{S}}^{*}=\mathrm{M}\left(\mathbf{m}_{\mathrm{s}}^{*}\right)$, since $\mathbf{m}_{\mathrm{s}}^{*}$ enters the contingency plans $\mathbf{f}$ only through $\mathrm{M}$.

At this point, we have completed our theoretical analysis of demand for money in a risky environment. We now can use GMM estimation to estimate the parameters of first order conditions under a particular specification for tastes. We then can compute the estimated theoretical monetary aggregate and proceed to investigate the quality of currently available statistical index numbers in tracking the monetary service flow. But we first determine the applicability of existing index number theory under the assumptions of our exact aggregation theory.

\section{The Risk Neutral Case}

In the perfect certainty case, nonparametric index number theory is highly developed and is applicable to monetary aggregation. In the perfect certainty case, Barnett $(1978,1980)$ proved that the nominal user cost of the services of $m_{i t}$ is $\pi_{i t}$, where

$$
\pi_{i t}=p_{t}^{*} \frac{R_{t}-r_{i t}}{1+R_{t}}
$$

The corresponding real user cost is $\pi_{\mathrm{it}} / \mathrm{p}^{*}$. In the risk neutral case, the user cost formulas are the same as in the perfect certainty case, but with the interest rates replaced by their expected values. It can be shown that the solution value of the exact monetary aggregate $M\left(\mathbf{m}_{t}\right)$ can be tracked without error in continuous time (see, e.g., Barnett (1983)) by the Divisia index: 


$$
\mathrm{d} \log \mathrm{M}_{\mathrm{t}}=\sum_{i=1}^{k_{1}} s_{i t} \mathrm{~d} \log \mathrm{m}_{\mathrm{it}}
$$

where the user cost evaluated expenditure shares are $\mathrm{s}_{\mathrm{it}}=\pi_{\mathrm{it}} \mathrm{m}_{\mathrm{it}} / \sum_{i=1}^{k_{1}} \pi_{\mathrm{jt}} \mathrm{m}_{\mathrm{jt}}$. The flawless tracking ability of the index in the risk neutral case holds regardless of the form of the unknown aggregator function, $\mathrm{M}$.

However, under risk aversion the ability of equation (16) to track $\mathrm{M}\left(\mathbf{m}_{\mathrm{t}}\right)$ is compromised. We investigate the magnitude of that error below by econometrically estimating $M\left(\mathbf{m}_{\mathrm{t}}\right)$.

\section{A Generalization}

The fact that the Divisia index tracks exactly under perfect certainty or risk neutrality is well know. However, we show in this section that neither perfect certainty nor risk neutrality are needed for exact tracking of the Divisia index. Only contemporaneous prices and interest rates need be known. Future interest rates and prices need not be known, and risk averse behavior relative to those stochastic processes need not be excluded. The proof is as follows.

Assume that $\mathrm{R}_{\mathrm{t}}, \mathrm{p}_{\mathrm{t}}^{*}$, and $\mathbf{r}_{\mathrm{t}}$ are known at time $\mathrm{t}$, although their future values are stochastic. Then the Euler equations (13a) for $\mathbf{m}_{\mathrm{t}}$ are

$$
\frac{\partial u}{\partial m_{i t}}-\rho p_{t}^{*}\left(R_{t}-r_{i t}\right) E_{t}\left[\frac{1}{p_{t+1}^{*}} \frac{\partial u}{\partial c_{t+1}}\right]=0
$$

for $\mathrm{i}=1, \ldots, \mathrm{k}_{1}$. Similarly the Euler equation (13b) for aggregate consumption of goods, $\mathrm{c}_{\mathrm{t}}$, becomes

$$
\frac{\partial u}{\partial c_{t}}-\rho p_{t}^{*}\left(1+R_{t}\right) E_{t}\left[\frac{1}{p_{t+1}^{*}} \frac{\partial u}{\partial c_{t+1}}\right]=0
$$

Eliminating $E_{t}\left[\frac{1}{p_{t+1}^{*}} \frac{\partial u}{\partial c_{t+1}}\right]$ between (17) and (18), we acquire 


$$
\frac{\partial u}{\partial m_{i t}}=\frac{R_{t}-r_{i t}}{1+R_{t}} \frac{\partial u}{\partial c_{t}}
$$

But by the assumption of weak separability of $\mathrm{u}$ in $\mathbf{m}_{\mathrm{t}}$, we have

$$
\frac{\partial u}{\partial m_{i t}}=\frac{\partial u}{\partial M_{t}} \frac{\partial M}{\partial m_{i t}}
$$

where $\mathrm{M}_{\mathrm{t}}=\mathrm{M}\left(\mathbf{m}_{\mathrm{t}}\right)$ is the exact monetary aggregate that we seek to track.

Substituting (19) into (20) and using (15), we find that

$$
\frac{\partial M}{\partial m_{i t}}=\pi_{i t} \frac{\partial u / \partial c_{t}}{\partial u / \partial M_{t}}
$$

Now substitute (21) into the total differential of $M$ to acquire

$$
d M\left(\mathbf{m}_{t}\right)=\frac{\partial u / \partial c_{t}}{\partial u / \partial M_{t}} \sum_{i=1}^{k_{1}} \pi_{i t} d m_{i t} .
$$

But since $\mathrm{M}$ is assumed to be linearly homogeneous, we have Euler's equation for linearly homogeneous functions. Substituting (21) into Euler's equation, we have

$$
M\left(\mathbf{m}_{t}\right)=\frac{\partial u / \partial c_{t}}{\partial u / \partial M_{t}} \sum_{j=1}^{k_{1}} \pi_{j t} m_{j t}
$$

Dividing (22) by (23), we acquire (16), which is the Divisia index. Hence the exact tracking property of the Divisia index is not compromised by uncertainty regarding future interest rates and prices or by risk aversion.

Nevertheless, this assumption is not trivial, as emphasized by Poterba and Rotemberg (1987), since current period interest rates are not paid until the end of the current period. In fact current period interest rates are not assumed contemporaneously known in our Euler equations (13a) and (13b). Barnett, Liu, and Jensen (1997) have derived the consumption CAPM beta risk adjustment to interest rates that removes the tracking error of the Divisia index under risk aversion. With 
that adjustment inserted in the user cost prices, Barnett, Liu, and Jensen (1997) proved that the Divisia index again tracks the aggregator function exactly in continuous time, regardless of the degree of risk aversion. But with the current controversies regarding CCAPM and the associated “equity premium puzzle," no central banks currently are using risk adjusted interest rates. In the current paper, we therefore do not include the risk adjusted Divisia index among the statistical index numbers that we compare for their ability to track the GMM estimated theoretical aggregator function.

\section{Data and Specification}

We conduct our comparisons at two levels of monetary aggregation: M1 and M2. In order to simplify the illustration, we accept a common clustering of M2 components without first testing for weak separability. We first set $\mathbf{m}_{\mathrm{S}}$ equal to those components of M1 found by Belongia and Chalfant (1989) to be weakly separable. ${ }^{5}$ We refer to the resulting aggregates over those components to be M1 aggregates. We then repeat our analysis with $\mathbf{m}_{\mathrm{s}}$ set equal to the components of $\mathrm{M} 2$, but with those components clustered into three groups with prior aggregation within groups, so that $\mathbf{m}_{\mathrm{S}}$ contains three aggregated elements. Hence we implicitly assume that $\mathbf{a}_{\mathrm{S}}$ is partitioned in accordance with a recursively nested two level separable blocking, such that the components of our M1 aggregate are separable within the components of our M2 aggregate, which in turn are separable within $\mathbf{a}_{\mathrm{s}}$. Considering the little that is known about testing for separability in the risk averse case, the clustering that we have chosen without explicit separability testing is hardly the last word on that subject.

We now select a specification for the function $\mathrm{u}$ satisfying our weak separability assumption, and we estimate the parameters by GMM. In that estimation, the data that we use is the monthly monetary component data available in Fayyad (1986) for January 1969 to March $1985 .{ }^{6}$ In our 
estimation of the parameters of tastes, we use that data in per capita real balances form. We begin by defining $\mathbf{m}_{\mathrm{S}}$ to contain two components: currency and demand deposits, which Belongia and Chalfant (1989) found to be blockwise weakly separable, at least under risk neutrality, from other goods and assets. ${ }^{7}$ In the utility function, $\mathrm{u}^{*}\left(\mathrm{M}\left(\mathbf{m}_{\mathrm{s}}\right), \mathbf{h}_{\mathrm{s}}, \mathbf{x}_{\mathrm{s}}\right)$, we assume a further higher level of nested blockwise strong separability, such that

$$
\mathrm{u}\left(\mathbf{m}_{\mathrm{s}}, \mathbf{h}_{\mathrm{s}}, \mathbf{x}_{\mathrm{s}}\right)=\mathrm{V}\left(\mathrm{M}\left(\mathbf{m}_{\mathrm{s}}\right), \mathrm{X}_{\mathrm{s}}\right)+\mathrm{H}\left(\mathbf{h}_{\mathrm{s}}\right),
$$

where $\mathrm{X}_{\mathrm{S}}=\mathrm{X}\left(\mathbf{x}_{\mathrm{s}}\right)$ is the exact quantity aggregate over consumer goods. ${ }^{8}$ The utility function that we specify and estimate is the category utility function $\mathrm{V}\left(\mathrm{M}\left(\mathbf{m}_{\mathrm{s}}\right), \mathrm{X}_{\mathrm{s}}\right){ }^{9}$

Since the variables in $\mathrm{V}\left(\mathrm{M}\left(\mathbf{m}_{\mathrm{s}}\right), \mathrm{X}_{\mathrm{S}}\right)$ are disjoint from those in $\mathrm{H}\left(\mathbf{h}_{\mathrm{s}}\right)$, we can restrict the original decision to be defined in terms of the utility function $\mathrm{V}\left(\mathrm{M}\left(\mathbf{m}_{\mathrm{s}}\right), \mathrm{X}_{\mathrm{s}}\right)$ in the following manner, without altering the solution for the variables $\left(\mathbf{m}_{\mathrm{s}}, \mathrm{X}_{\mathrm{s}}\right)$. We redefine the utility function in Problem 2 to be

$$
\mathrm{V}\left(\mathrm{M}\left(\mathbf{m}_{\mathrm{t}}\right), \mathrm{X}_{\mathrm{t}}\right)+\mathrm{E}_{\mathrm{t}}\left[\sum_{s=t+1}^{\infty}\left(\frac{1}{1+\xi}\right)^{\mathrm{s}-\mathrm{t}} \mathrm{V}\left(\mathrm{M}\left(\mathbf{m}_{\mathrm{s}}\right), \mathrm{X}_{\mathrm{s}}\right)\right]
$$

The utility function in Problem 1 can be restricted in the analogous manner. The budget constraint in either case is simplified in the following manner. All terms containing the variables $\left(\mathbf{h}_{\mathrm{s}}, \mathbf{h}_{\mathrm{s}-1}\right)$ are absorbed into the "other income" variable, $\mathrm{I}_{\mathrm{S}}$, with $\left(\mathbf{h}_{\mathrm{s}}, \mathbf{h}_{\mathrm{s}-1}\right)$ replaced by their stochastic processes solving the complete unrestricted decision (Problem 1 or 2).

The budget constraint then becomes:

$$
\begin{aligned}
& \left\{\left(\mathbf{m}_{\mathrm{s}}, \mathrm{X}_{\mathrm{s}}, \mathrm{A}_{\mathrm{s}}\right) \in \mathrm{H}: \mathrm{p}_{\mathrm{s}}^{*} \mathrm{X}_{\mathrm{s}}=\right. \\
+ & \left.\sum_{\mathrm{i}=1}^{\mathrm{k} 1}\left[\left(1+\mathrm{r}_{\mathrm{i}, \mathrm{s}-1}\right) \mathrm{p}_{\mathrm{s}-1}^{*} \mathrm{~m}_{\mathrm{i}, \mathrm{s}-1}-\mathrm{p}_{\mathrm{s}}^{*} \mathrm{~m}_{\mathrm{is}}\right]+\left(1+\mathrm{R}_{\mathrm{s}-1}\right) \mathrm{p}_{\mathrm{s}-1}^{*} \mathrm{~A}_{\mathrm{s}-1}-\mathrm{p}_{\mathrm{s}}^{*} \mathrm{~A}_{\mathrm{s}}+\mathrm{I}_{\mathrm{s}}\right\} .
\end{aligned}
$$


In short, with M1 components we estimate a three goods model, including two monetary components and the aggregate quantity of consumer goods, $\mathrm{X}_{\mathrm{s}}$. With $\mathrm{M} 2$ components we estimate a four goods model, including three aggregated monetary components and the aggregate quantity of consumer goods, $\mathrm{X}_{\mathrm{S}}$. We now define our specification for $\mathrm{V}^{10}$

We assume constant proportional risk aversion, such that the utility function $\mathrm{V}=\mathrm{V}\left(\mathrm{M}\left(\mathbf{m}_{\mathrm{S}}\right), \mathrm{X}_{\mathrm{S}}\right)$ is of the form

$$
\mathrm{V}\left(\mathrm{M}\left(\mathbf{m}_{\mathrm{S}}\right), \mathrm{X}_{\mathrm{S}}\right)=\frac{1}{\sigma}\left[\mathrm{J}\left(\mathrm{X}_{\mathrm{S}}, \mathrm{M}_{\mathrm{S}}\right)\right]^{\sigma}
$$

for some function, $\mathrm{J}$, where $\mathrm{M}_{\mathrm{S}}=\mathrm{M}\left(\mathbf{m}_{\mathrm{S}}\right)$ is the Theoretical monetary aggregate we seek to estimate. We then assume that the function $\mathrm{J}$ has the Cobb-Douglas form

$$
\mathrm{J}\left(\mathrm{X}_{\mathrm{S}}, \mathrm{M}_{\mathrm{S}}\right)=\mathrm{X}_{s}^{\beta} \mathrm{M}_{s}^{1-\beta}
$$

Finally we assume that the monetary aggregator function, $\mathrm{M}\left(\mathbf{m}_{\mathrm{S}}\right)$, has the CES (constant elasticity of substitution) form

$$
\mathrm{M}_{\mathrm{S}}=\left(\sum_{i=1}^{k_{1}} \delta_{\mathrm{i}} \mathrm{m}_{\mathrm{Si}}\right)^{1 / v}
$$

with $\sum_{i=1}^{n} \delta_{\mathrm{i}}=1$, where $\mathrm{n}=2$ for M1 and $\mathrm{n}=3$ for M2.

Substituting (29) into (28), and then substituting the result into (27), we get

$$
\mathrm{V}\left(\mathrm{M}\left(\mathbf{m}_{\mathrm{S}}\right), \mathrm{X}_{\mathrm{s}}\right)=\frac{1}{\sigma}\left[\mathrm{X}_{s}^{\beta}\left(\sum_{i=1}^{k_{1}} \delta_{\mathrm{i}} \mathrm{m}_{\mathrm{si}}\right)(1-\beta) / v\right] \sigma
$$

Denoting the rate of subjective time discount by $\rho=1 /(1+\xi)$ and substituting (30) into (25), we get the complete intertemporal expected utility function

$$
\mathrm{E}_{\mathrm{t}}(\mathrm{U})=\frac{1}{\sigma}\left[\mathrm{X}_{t}^{\beta}\left(\sum_{i=1}^{k_{1}} \delta_{\mathrm{i}} \mathrm{m}_{\mathrm{ti}}\right)^{(1-\beta) / v}\right]^{\sigma}+\mathrm{E}_{\mathrm{t}}\left[\sum_{s=t+1}^{\infty} \rho^{\mathrm{s}-\mathrm{t}} \frac{1}{\sigma}\left[\mathrm{X}_{s}^{\beta}\left(\sum_{i=1}^{k_{1}} \delta_{\mathrm{i}} \mathrm{m}_{\mathrm{si}}\right)^{(1-\beta) / v}\right] \sigma\right]
$$


The parameters to be estimated are $\rho, \sigma, \beta,\left\{\delta_{i}\right\}$, and $v$. The constraints imposed on those parameters are

$$
\sum_{i=1}^{k_{1}} \delta_{\mathrm{i}}=1,0<\beta \leq 1, \text { and } 0<\delta_{\mathrm{i}} \leq 1
$$

All consumption and asset quantity data are real per capita. We approximate the benchmark rate, $R_{S}$, by the maximum holding period yield across all assets in Fayyad's (1986) tables during period s. The particular asset which produced that rate of return need not be the same for all $\mathrm{s}$, since our measurement of $\mathrm{R}_{\mathrm{s}}$ produces a proxy for the rate of return on some very illiquid asset (such as human capital in a world without slavery), on which we may have no monthly data.

\section{Estimation}

We use Hansen and Singleton's (1982) generalized method of moments estimator to estimate the parameters of the Euler equations, (13a) and (13b). In accordance with Hansen and Singleton's estimator, we iterate on the weighting matrix until convergence. The Hansen and Singleton GMM estimator requires the selection of instrumental variables. When estimating the Theoretical M1 aggregate, we use the following five instruments: $Z_{1}=$ constant $=10$, $\mathrm{Z}_{2}=\mathrm{X}_{\mathrm{s}-1}-\mathrm{X}_{\mathrm{s}}, \mathrm{Z}_{3}=\left(\mathrm{m}_{\mathrm{s}+1,1}-\mathrm{m}_{\mathrm{s} 1}\right)+\left(\mathrm{m}_{\mathrm{s}+1,2}-\mathrm{m}_{\mathrm{s} 2}\right), \mathrm{Z}_{4}=\mathrm{m}_{\mathrm{s}-1,1}+\mathrm{m}_{\mathrm{s}-1,2}$, and $\mathrm{Z}_{5}=\mathrm{R}_{\mathrm{s}-1}$.

The sample size in Fayyad (1986) is 195 which covers monthly periods from January of 1969 to March of 1985. In order to impose the constraints on the parameters, we transform the parameters in the following manner:

$$
\sum_{i=1}^{k_{1}} \rho=\mathrm{B}_{1}, \sigma=\mathrm{B}_{2}, \beta=\cos ^{2} \mathrm{~B}_{3}, \delta=\cos ^{2} \mathrm{~B}_{4}, \nu=\mathrm{B}_{5}
$$

and we estimate the new parameters $\mathrm{B}_{1}, \mathrm{~B}_{2}, \mathrm{~B}_{3}$, and $\mathrm{B}_{4}$. The GMM estimator converged at its 
fourth stage. The resulting parameter estimates are as in Table $1 .{ }^{11}$ Using these parameter estimates and the component data, the estimated theoretical M1 monetary aggregate, $\mathrm{M}_{\mathrm{S}}=$ $\mathrm{M}\left(\mathbf{m}_{\mathrm{S}}\right)$, was computed at each observation. We also computed the Divisia quantity index and the simple sum index over the same components.

This procedure then was repeated with the M2 data. The components of M2 were clustered into three groups, and asset quantities within the groups were aggregated by simple summation to produce three aggregated components over which we then aggregate by the three methods. For details of the prior clustering of components, see Table 4-1 in Barnett, Hinich, and Yue (1991). In order to impose the constraints on the parameters, we transform them as follows

$$
\rho=\mathrm{B}_{1}, \sigma=\mathrm{B}_{2}, \beta=\cos ^{2} \mathrm{~B}_{3}, \delta_{1}=\cos ^{2} \mathrm{~B}_{5}, \quad \delta_{2}=\sin ^{2} \mathrm{~B}_{5} \sin ^{2} \mathrm{~B}_{6}, v=\mathrm{B}_{4} .
$$

The GMM estimation converged at the third stage. The resulting parameter estimates are provided in Table 2 .

Using these parameter estimates and the component data, the estimated theoretical M2 monetary aggregate, $\mathrm{M}_{\mathrm{S}}=\mathrm{M}\left(\mathbf{m}_{\mathrm{s}}\right)$, was computed at each observation. We also computed the Divisia quantity index and the simple sum index over the same components. In Figure 1, the nominal per capita monetary indices are supplied for the three methods of aggregation at both the M1 and M2 levels of aggregation.

The properties of the three aggregates at each level of aggregation are easily seen by inspecting Figure 1. At both levels of aggregation, the Divisia index tracked the estimated Theoretical aggregate more closely than did the simple sum monetary aggregate. At the M1 level, Divisia M1 tracks the estimated Theoretical aggregate rather well throughout the sample period. At the M2 level, the growth rates of the Divisia and estimated Theoretical aggregates diverged from each other from September 1982 through April 1983, with the growth rate of the 
estimated Theoretical aggregate being consistently higher than that of the Divisia aggregate throughout that time period. This phenomenon opened a gap between the plots of the levels of the two series. However, the two paths tracked parallel to each other after the eight months of diverging growth rates, since the growth rates of the two series returned to being very similar after April 1983.

The source of the divergence from September 1982 through April 1983 probably can be found in the unusual circumstances that existed in money markets. Many innovations in money markets evolved during that period, such as the introduction of super-NOW accounts and moneymarket deposit accounts at commercial banks. ${ }^{12}$ There also was more than the usual degree of uncertainty regarding monetary policy, since that period immediately followed the termination of the Federal Reserve's "monetarist experiment," and the targets of monetary policy immediately following the termination of that experiment were unclear. In short, we find that the Divisia monetary aggregates would have benefited from Barnett, Liu, and Jensen’s (1997) risk adjustment only during that one period of unusually high risk in money markets.

\section{Frequency Domain Tests:}

In earlier research, Barnett, Gallant, Hinich, Jungeilges, Kaplan, and Jensen (1995) detected nonlinearity in the Divisia monetary aggregate time series. In this paper, we seek to determine whether the time series of the estimated Theoretical monetary aggregates exhibit similar nonlinearity, and whether the nonlinearity in the Divisia monetary aggregate stochastic process is induced by the nonlinearity in the Theoretical aggregate process that the Divisia index is tracking. In particular, we wish to investigate whether there exists any remaining nonlinear 
structure in the difference between the Divisia and estimated Theoretical monetary aggregate. We use this test as a form of residual analysis to explore the dynamic properties of the Divisia index as an approximation to the Theoretical aggregate.

The mathematical theory relating the normalized squared skewness function to linearity and Gaussianity has been used to derive testing procedures by Hinich (1982) and Rao and Gabr (1980). The procedure used in this paper is the one derived in Hinich (1982). Details of the Hinich test are also discussed in Hinich and Patterson $(1985,1989)$ and Ashley, Hinich, and Patterson (1986).

There are an infinite number of polyspectra, where the order of the polyspectra are determined by the number of frequencies in their Fourier transform. The bispectrum, having two frequencies (its "bifrequencies"), is the second order polyspectrum. The Hinich test is based upon the skewness function, which is the normalized bispectrum, normalized by division by the product of the ordinary power spectra of the two individual frequencies and their sum.

The conventional methods of bispectrum estimation are reviewed in Nikias and Raghuveer (1987). The bispectrum can be estimated consistently from a finite sample $\{x(1), \ldots, x(N)\}$ by the following procedure. Segment the record of $\mathrm{N}$ observations into K (non-overlapped) blocks of $\mathrm{L}$ observations each, where $\mathrm{L}$ is called the block-length. ${ }^{13}$ The parameter $\mathrm{K} / \mathrm{N}=1 / \mathrm{L}$, is the resolution bandwidth. ${ }^{14}$ For $\mathrm{k}=1, \ldots, \mathrm{K}$, define the bi-periodogram for the bifrequency pair $\left(\mathrm{f}_{\mathrm{i}}, \mathrm{f}_{\mathrm{j}}\right)$ as

$$
G_{k}\left(f_{i}, f_{j}\right)=\frac{1}{L} X_{k}\left(f_{i}\right) X_{k}\left(f_{j}\right) X_{k}^{*}\left(f_{i}+f_{j}\right),
$$

where $X_{k}(f)=\sum_{n=(k-1) L+1}^{k L} x(n) \exp [-i 2 \pi f n / N]$ and where $X_{k}^{*}$ denotes the complex conjugate of $X_{\mathrm{k}}$.

A consistent and asymptotically normal estimator of the bispectrum is 


$$
\hat{B}_{x x x}\left(f_{i}, f_{j}\right)=\frac{1}{K} \sum_{k=1}^{K} G_{k}\left(f_{i}, f_{j}\right),
$$

where $2 f_{i}+f_{j}<N$ and $0<f_{j}<f_{i}<N$, and $f_{i}=i / L(i=1,2, \ldots, L)$. See Hinich and Messer (1995) for details on the estimator. ${ }^{15}$ This type of estimator is analogous to the direct estimator of the power spectrum described in Welch (1967) and Groves and Hannan (1968), in which the data record is segmented into frames, and periodograms are computed frame by frame, and then averaged at each frequency.

The lowest order polyspectrum, having only one frequency, is the ordinary power spectrum. The power spectrum estimator is

$$
\hat{P}_{x x}\left(f_{i}\right)=\frac{1}{K} \sum_{k=1}^{K} I_{k}\left(f_{i}\right)
$$

where the periodogram is defined as $I_{k}\left(f_{i}\right)=\frac{1}{2 \pi L} X_{k}\left(f_{i}\right) X_{k}^{*}\left(f_{i}\right), \mathrm{k}=1,2, \ldots, \mathrm{K} .{ }^{16}$ In the bispectrum case, bi-periodograms are computed frame by frame and then averaged at each frequency pair. It is the final averaging step which leads to consistency of the estimator in both cases. The variance is reduced by averaging over more frames, but at a cost of reduced resolution. ${ }^{17}$

We estimate the bispectrum over a range of values for the block length, L, in accordance with a suggestion of Stokes (1991). The suggested range of block lengths is $(\mathrm{N} / 3)^{1 / 2}$ to $(\mathrm{N})^{1 / 2}$, which, for our sample size $(\mathrm{N}=396)$, corresponds to a range of block lengths between 12 and 19. See Stokes (1991) for an example using a well known gas data model. The setting $\mathrm{L}=12$, corresponds to $\mathrm{N}^{.42}$ and is the closest to Hinich's suggestion of $\mathrm{N}^{4}$.

The Hinich test for nonlinearity produces a test statistic Z, which is distributed asymptotically as the standard normal under the null hypothesis of constant skewness. Linear stochastic 
processes have constant skewness for all pairs of frequencies. The test corresponds to a test of flatness of the bispectrum against variations in the frequency pair. If the bispectrum is not flat, the power of clashes between frequency pairs depends upon the frequency pair. If that power is not only independent of the frequency pair, but is always zero, then the process has satisfied a necessary condition for Gaussianity, which is a special case of linearity. The conditions for linearity and Gaussianity would not only be necessary but also sufficient, if the conditions also applied to all higher order polyspectra. The Hinich Gaussianity test produces a test statistic G, which is asymptotically standard normal under the null of zero skewness, which corresponds to flatness of the bispectrum at zero power. Both the linearity and Gaussianity tests are one sided, and the null is rejected if the test statistics are large.

The Hinich test is extremely conservative. If the stochastic processes $x(t)$ is linear, then all of its polyspectra of order greater than or equal to two are independent of the frequency n-tuples, $\left(f_{1}, f_{2}, \ldots, f_{n}\right)$, for all $n \geq 2$. But the Hinich test is based only on the bispectrum having $n=2$. A rejection of its null would be a strong result, because the null includes all linear processes and some nonlinear processes. Consequently, the Hinich test cannot confirm linearity. It only can reject or fail to reject it. In principle, we could test for nonlinearities using polyspectra of higher order than the bispectrum, but estimation of even the trispectrum is not feasible for common sample sizes of economic data sets.

The conservatism of the Hinich test has been reflected in empirical studies. For example, Barnett, Gallant, Hinich, Jungeilges, Kaplan, and Jensen (1997) find that the Hinich test was much less likely to reject its null than other competing tests, such as the BDS test (Brock, Dechert, Scheinkman, and LeBaron (1996)). In addition, Hong (1996) notes that the third order cumulants of an ARCH (autoregressive conditional heteroskedastic) process can be identically 
zero, in which case the bispectrum test would fail to reject linearity. Barnett, Gallant, Hinich, Jungeilgies, Kaplan, and Jensen (1997) demonstrate that empirically the Hinich test has low power against ARCH. In fact ARCH is linear in the mean, and Ashley, Hinich, and Patterson (1986) have shown that the Hinich nonlinearity test does have substantial power (at reasonable sample sizes) against many commonly considered forms of nonlinear serial dependence.

The Hinich test has been applied previously in economic analysis. Hinich and Patterson (1989) examine trade by trade stock market data for evidence of nonlinearity. Barnett, Gallant, Hinich, Jungeilges, Kaplan, and Jensen (1995) find that Divisia monetary aggregate growth rate data exhibit deep nonlinearity at the M1 level of aggregation. The value of the asymptotic Z statistic for Divisia M1 in their test was 21.66, far exceeding customary rejection levels of 2 or 3. Considering the conservative nature of the test, this rejection of linearity is dramatic.

\section{Frequency Domain Results}

With the same monthly nominal per capita growth rate data used by Barnett, Gallant, Hinich, Jungeilges, Kaplan, and Jensen (1995) and by Barnett, Hinich, and Yue (1991), we run the same bispectrum tests for nonlinearity, but for the difference between the growth rate of the Divisia monetary aggregate and its corresponding GMM estimated Theoretical monetary aggregate. At the M1 level of aggregation, the Hinich asymptotic Z statistic for testing nonlinearity of that tracking error is 1.322 . Hence we cannot reject linearity of the residual process for the Divisia approximation. We conclude that the strong evidence of nonlinearity found in the Divisia monetary aggregate M1 data by Barnett, Gallant, Hinich, Jungeilges, Kaplan, and Jensen (1995) was induced by the stochastic process of the exact Theoretical monetary aggregate that is tracked by the corresponding Divisia monetary aggregate. 
At the M2 level, Barnett, Gallant, Hinich, Jungeilges, Kaplan, and Jensen (1995) found little evidence of nonlinearity in the Divisia monetary aggregate's stochastic process. The Hinich asymptotic $\mathrm{Z}$ statistic was 1.542 , and hence they could not reject linearity. At that level of aggregation, we similarly find little evidence of nonlinearity in the residual process. The Hinich $\mathrm{Z}$ statistic for the difference in growth rates between the Divisia and estimated Theoretical M2 aggregate is 1.426 . Hence there was little nonlinear structure for Divisia to remove from the Theoretical aggregate's time series at the M2 level, and little nonlinear structure is evident in the tracking errors.

Since sample size is important in the Hinich test, we decided to determine whether nonlinearity would become evident in Divisia M2 when the data is updated to include the latest observations reported by the Federal Reserve Bank of St. Louis. We repeated the Hinich test with the full available sample size of monthly Divisia M2 data. The sample is from January 1959 through October 1999 and is seasonally adjusted. We converted it to per capita form by division by noninstitutional population and transformed to growth rates. We ran the Hinich test for nonlinearity with that data, both with and without deflation to real balances using the consumer price index as the deflator. In addition to computing Hinich's asymptotic Z statistic to test for linearity, we also bootstrapped his test statistic to acquire a finite sample inference.

The bootstrap method used was to resample the data 300 times and compute the $\mathrm{Z}$ statistic for each resample. The $300 \mathrm{Z}$ statistics are then sorted, and the $95 \%, 96 \%, 97 \%, 98 \%, 99 \%, 99.5 \%$, and $99.9 \%$ quantiles are computed. The level of the $95 \%$ quantile is the threshold to use for the $\mathrm{Z}$ statistic, if one wants to achieve a $5 \%$ size for the test based on the resampling method.

For the per capita real growth rate data, the asymptotic $\mathrm{Z}$ statistic was 0.26 and the $95 \%$ quantile of the bootstrapped $Z$ was 1.19 . With the per capita real nominal growth rate data, the 
asymptotic $\mathrm{Z}$ statistic was 0.96 and the $95 \%$ quantile of the bootstrapped $\mathrm{Z}$ was 1.01 . Hence there is even less evidence of statistically significant nonlinearity in the Divisia M2 data in the large sample than in the original smaller sample using the Hinich asymptotic $\mathrm{Z}$ statistic.

Nevertheless, it is interesting to inspect the estimated bispectrum. That three dimensional surface can contain information about the frequency pairs at which nonlinear interactions might exist, even if the inference about general nonlinearity is statistically insignificant. Recall that the test seeks to detect deviations from flatness of the skewness function (the normalized bispectrum). The skewness function is the square of the absolute value of the bispectrum divided by the product of the spectra of the bifrequencies and their sum.

Rather than plotting the skewness values, we plot the normal cumulative distribution of the skewness multiplied by a scale factor to make skewness have a chi square distribution with two degrees-of-freedom, using the mean non-centrality parameter for each bifrequency pair. Again the theory is developed for a large sample, but simulations have shown that the results are conservative. Thus the values plotted are the probabilities of obtaining such a value of the skewness at that bicorrelation under the null of linearity. In figure 2 we display the skewness function plotted against the two periods (inversely related to the two frequencies) for the per capita real growth rate Divisia M2 data. The view is looking down from above, and the color code designates height. ${ }^{18}$ Although the true bispectrum and normalized skewness function are smooth functions, Hinich's test uses discrete bifrequencies in accordance with the sampling procedure described above. With this extended sample, we used a resolution bandwidth in monthly time units of 12 months, which produces nine bifrequencies. Figure 2 displays level surfaces corresponding to the tops of the boxes produced in estimating the bispectrum and skewness functions from the finite samples. 
It was evident from the plots of the nominal and real per capita Divisia M2 data that the estimated skewness function is not flat versus frequency (or period) pairs. The (4 month, 4 month) bifrequency for the nominal data has a probability value of 0.971 . If we believe that the use of asymptotic theory is valid, then the probability of obtaining such a result for one of the nine bifrequencies is $2.9 \%$. This result suggests that there is some nonlinear structure remaining in that data, although in the test of general nonlinearity we cannot reject the null of linearity. We do not supply that plot, but we do supply the corresponding plot for the deflated real data. Figure 2 was produced from that deflated real data. Inspection of Figure 2 suggests that deflation to real balances filtered out whatever little nonlinearity existed in the nominal data. In particular, in Figure 2 we see that the largest probability value for the real data is 0.944 for the (12 month, 4 month) bifrequency.

\section{Conclusions}

We conclude from the M1 level data that the nonlinear serial dependence in the Divisia M1 stochastic process was induced from the nonlinearity in the exact Theoretical aggregate that the Divisia index tracks. No statistically significant nonlinearity remains in the tracking error process, so we find that the Divisia index successfully extracted the nonlinearity from the theoretical aggregate's process. At the M1 level of aggregation, we find no evidence of significant gains from the use of the risk adjusted Divisia monetary aggregate, so our frequency domain tests are based upon the tracking ability of the unadjusted Divisia M1 index.

At the M2 level, we find that the use of the CCAPM beta adjusted Divisia monetary aggregate would be advantageous only during a brief period of a few months. That period was one during which the level of risk in the financial sector of the economy was unusually high. 
Risk aversion does not seem to be a significant problem for the unadjusted Divisia monetary aggregates, except at broad levels of aggregation during periods of unusually high risk. 


\section{References}

Arrow, K. J. and F. Hahn (1971) General Competitive Analysis. San Francisco, Holden-Day.

Ashley R., D. Patterson and M. Hinich (1986) A Diagnostic Test for Non-linear Serial Dependence in Time Series Fitting Errors. Journal of Time Series Analysis 7, 165-178.

Barnett. W. A. (1980) Economic Monetary Aggregates: An Application of Index Number and Aggregation Theory. Journal of Econometrics 14, 11-48. Reprinted as chapter 2 in W. A. Barnett and A. Serletis (eds.) (2000) The Theory of Monetary Aggregation. Amsterdam: North Holland.

Barnett, W. A. (1983) Understanding the New Divisia Monetary Aggregates. Review of Public Data Use (now called Journal of Economic and Social Measurement) 11, 31-35. Reprinted as chapter 4 in W. A. Barnett and A. Serletis (eds.) (2000) The Theory of Monetary Aggregation. Amsterdam: North Holland.

Barnett, W. A. (1987) The Microeconomic Theory of Monetary Aggregation. In W. A. Barnett and K. J. Singleton (eds.) New Approaches to Monetary Economics, Cambridge University Press. Reprinted as chapter 3 in W. A. Barnett and A. Serletis (eds.) (2000) The Theory of Monetary Aggregation. Amsterdam: North Holland.

Barnett, W. A., A. R. Gallant, M. J. Hinich, J. A. Jungeilges, D. T. Kaplan, and M. J. Jensen (1995) Robustness of Nonlinearity and Chaos Tests to Measurement Error, Inference Method, and Sample Size. Journal of Economic Behavior and Organization, vol. 27. 301-320. 
Barnett, W. A., A. R. Gallant, M. J. Hinich, J. A. Jungeilges, D. T. Kaplan, and M. J. Jensen (1997) A Single Blind Controlled Competition Among Tests For Non-linearity and Chaos. Journal of Econometrics, vol. 77. 297-302.

Barnett, W. A and A. Serletis (eds.) (2000) The Theory of Monetary Aggregation. Amsterdam: North Holland.

Barnett, W. A., D. Fisher, and A. Serletis (1992) Consumer Theory and the Demand for Money. Journal of Economic Literature 92, 2086-119. Reprinted as chapter 18 in W. A. Barnett and A. Serletis (eds.) (2000) The Theory of Monetary Aggregation. Amsterdam: North Holland.

Barnett, W. A., J. Geweke and M. Wolfe (1991a) Seminonparametric Bayesian Estimation of the Asymptotically Ideal Production Model. Journal of Econometrics 49, 5-50.

Barnett, W. A., J. Geweke, and M. Wolfe (1991b) Seminonparametric Bayesian Estimation of Consumer and Factor Demand Models. In W. A. Barnett, B. Cornet, C. D'Aspremont, J. Gabszewicz, and A. Mas-Colell (eds.) Equilibrium Theory and Applications. Cambridge: Cambridge University Press, 425-480.

Barnett, W. A., J. Geweke, and P. Yue (1991) Seminonparametric Bayesian Estimation of the Asymptotically Ideal Model: The AIM Demand System. In W. A. Barnett, G. Tauchen, and J. Powell (eds.) Nonparametric and Semiparametric Methods in Econometrics and Statistics. Cambridge: Cambridge University Press, 127-174.

Barnett, W. A., M. Hinich, and P. Yue (1991) Monitoring Monetary Aggregates under Risk Aversion. In M. T. Belongia (ed.) Monetary Policy on the 75th Anniverary of the Federal Reserve System. Amsterdam: Kluwer, 189-222. Reprinted as chapter 11 in W. A. 
Barnett and A. Serletis (eds.) (2000) The Theory of Monetary Aggregation. Amsterdam: North Holland.

Barnett, W. A., M. Kirova, and M. Pasupathy (1995) Estimating Policy-Invariant Deep Parameters in the Financial Sector When Risk and Growth Matter. Journal of Money, Credit, and Banking 27, 1402-1430. Reprinted as chapter 22 in W. A. Barnett and A. Serletis (eds.) (2000) The Theory of Monetary Aggregation. Amsterdam: North Holland.

Barnett, W. A., Yi Liu, and Mark Jensen (1997) CAPM Risk Adjustment for Exact Aggregation over Financial Assets. Macroeconomic Dynamics 1, 485-512. Reprinted as chapter 12 in W. A. Barnett and A. Serletis (eds.) (2000) The Theory of Monetary Aggregation. Amsterdam: North Holland.

Barnett, W. A. and G. Zhou (1994) Financial Firm's Production and Supply-Side Monetary Aggregation Under Dynamic Uncertainty. St. Louis Federal Reserve Bank's Monthly Review 76, 133-165. Reprinted as chapter 21 in W. A. Barnett and A. Serletis (eds.) (2000) The Theory of Monetary Aggregation. Amsterdam: North Holland.

Belongia, M. T. (1996) Measurement Matters: Recent Results from Monetary Economics Reexamined. Journal of Political Economy 104, 1065-1083.

M. T. Belongia and J. E. Binner (eds.) (2000) Divisia Monetary Aggregates: Theory and Practice. London, Macmillan Press Ltd.

Belongia, M. and J. Chalfant (1989) The Changing Empirical Definition of Money: Some Estimates from a Model of the Demand for Money Substitutes. Journal of Political Economy 97, 387-398.

Brock, W. A., W. D. Dechert, J. Scheinkman, and B. LeBaron (1996) A Test for Independence Based on the Correlation Dimension. Econometric Reviews 15, 197-235. 
Chrystal, K. A. and R. MacDonald (1994) Empirical Evidence on the Recent Behavior and Usefulness of Simple-Sum and Weighted Measures of the Money Stock. Federal Reserve Bank of St. Louis Review 76, 73-109.

Fayyad, S. K. (1986) Monetary Asset Component Grouping and Aggregation: An Inquiry into the Definition of Money. Ph. D. dissertation, University of Texas, Austin, Texas.

Feenstra, R. C. (1986) Functional Equivalence Between Liquidity Costs and the Utility of Money. Journal of Monetary Economics 17, 271-291.

Groves, G. W. and E. J. Hannan (1968) Time Series Regression of Sea Level on Weather. Reviews of Geophysics 6, 129-174.

Hansen, L. P. and K. Singleton (1982) Generalized Instrumental Variable Estimation of Nonlinear Rational Expectations Models. Econometrica, 50.

Hinich, M. J. (1982) Testing for Gaussianity and Linearity of a Stationary Time Series. Journal of Time Series Analysis 3, 169-176.

Hinich, M. J. and G. R. Messer (1995) On the Principle Domain of the Discrete Bispectrum of a Stationary Signal. IEEE Transactions on Signal Processing 43, 2130-2134.

Hinich, M. J. and D. Patterson (1985) Identification of the Coefficients in a Non-linear Time Series of the Quadratic Type. Journal of Econometrics 30, 269-288.

Hinich, M. J. and D. Patterson (1989) Evidence of Non-linearity in the Trade by Trade Stock Market Return Generating Process. In W. Barnett, J. Geweke, and K. Shell (eds.) Economic Complexity: Chaos, Sunspots, Bubbles and Non-linearity, Proc. 4th Int. Symp. on Economic Theory and Econometrics. Cambridge: Cambridge University Press.

Hong, Y. (1996) Consistent Testing for Serial Correlation of Unknown Form. Econometrica 64, $837-864$. 
Phlips, L. and F. Spinnewyn (1982) Rationality versus Myopia in Dynamic Demand Systems. In R. L. Basmann and G. F. Rhodes (eds.) Advances in Econometrics, Greenwich, CT: JAI Press, 3-33.

Poterba, J. M. and J. J. Rotemberg (1987) Money in the Utility Function: An Empirical Implementation. In W. A. Barnett and K. J. Singleton (eds.) New Approaches to Monetary Economics. Cambridge, Cambridge University Press 219-240.

Stokes, Houston (1991) Specifying and Diagnostically Testing Econometric Models. London: Quorum Books.

Swofford, J. L. and Whitney, G. A. (1987) Nonparametric Test of Utility Maximization and Weak Separability for Consumption, Leisure, and Money. Review of Economics and Statistics 69, 458-64.

Thornton, D. and P. Yue (1992) An Extended Series of Divisia Monetary Aggregates. Federal Reserve Bank of St. Louis Review 74, 35-52.

Welch, P. D. (1967) The Use of Fast Fourier Transform for the Estimation of Power Spectra: A Method Based on Time Averaging Over Short Modified Periodograms. IEEE Transactions on Audio and Electroacoustics. AU-15, 70-73. 
Table 1

GMM Estimates of Parameters of M1 Theoretical Aggregator Function Nested within Consumer Demand Model

\begin{tabular}{|c|c|c|c|c|c|}
\hline \multirow[b]{2}{*}{$\begin{array}{l}\text { Estimated Parameter } \\
\text { Estimate } \\
\text { t-ratio }\end{array}$} & \multicolumn{2}{|c|}{ Inside Aggregator } & \multicolumn{3}{|c|}{ Outside Aggregator } \\
\hline & $\begin{array}{c}\mathrm{B} 1 \\
0.9168 \\
62.489\end{array}$ & $\begin{array}{c}\mathrm{B}_{2} \\
-0.3329 \\
-3.726\end{array}$ & $\begin{array}{c}\mathrm{B} 3 \\
7.6018 \\
19.171\end{array}$ & $\begin{array}{c}\mathrm{B} 4 \\
42.717 \\
10.424\end{array}$ & $\begin{array}{c}\mathrm{B} 5 \\
0.6800 \\
2.3769\end{array}$ \\
\hline $\begin{array}{l}\text { Derived Parameter } \\
\text { Implied Estimate }\end{array}$ & $\begin{array}{c}\rho \\
0.9168\end{array}$ & $\begin{array}{c}\alpha \\
-0.3329\end{array}$ & $\begin{array}{c}\beta \\
0.9825\end{array}$ & $\begin{array}{c}\delta \\
0.5398\end{array}$ & $\begin{array}{c}v \\
0.6800\end{array}$ \\
\hline
\end{tabular}


Table 2

GMM Estimates of Parameters of M2 Theoretical Aggregator Function Nested within Consumer Demand Model

Inside Aggregator Outside Aggregator

\begin{tabular}{l|ccc|ccc}
\cline { 2 - 7 } Estimated Parameter & $\mathrm{B} 1$ & $\mathrm{~B}_{2}$ & $\mathrm{~B} 3$ & $\mathrm{~B} 4$ & $\mathrm{~B} 5$ & $\mathrm{~B} 6$ \\
$\begin{array}{l}\text { Estimate } \\
\text { t-ratio }\end{array}$ & 0.8975 & -0.2669 & 0.2173 & 0.8426 & 0.8198 & 0.9177 \\
& 43.9094 & -3.3072 & 13.1376 & 1.9011 & 17.6566 & 14.6081 \\
\hline $\begin{array}{l}\text { Derived Parameter } \\
\text { Implied Estimate }\end{array}$ & $\rho$ & $\sigma$ & $\beta$ & & & \\
& 0.8975 & -0.2669 & 0.9535 & 0.8426 & 0.4656 & 0.3371 \\
\hline
\end{tabular}




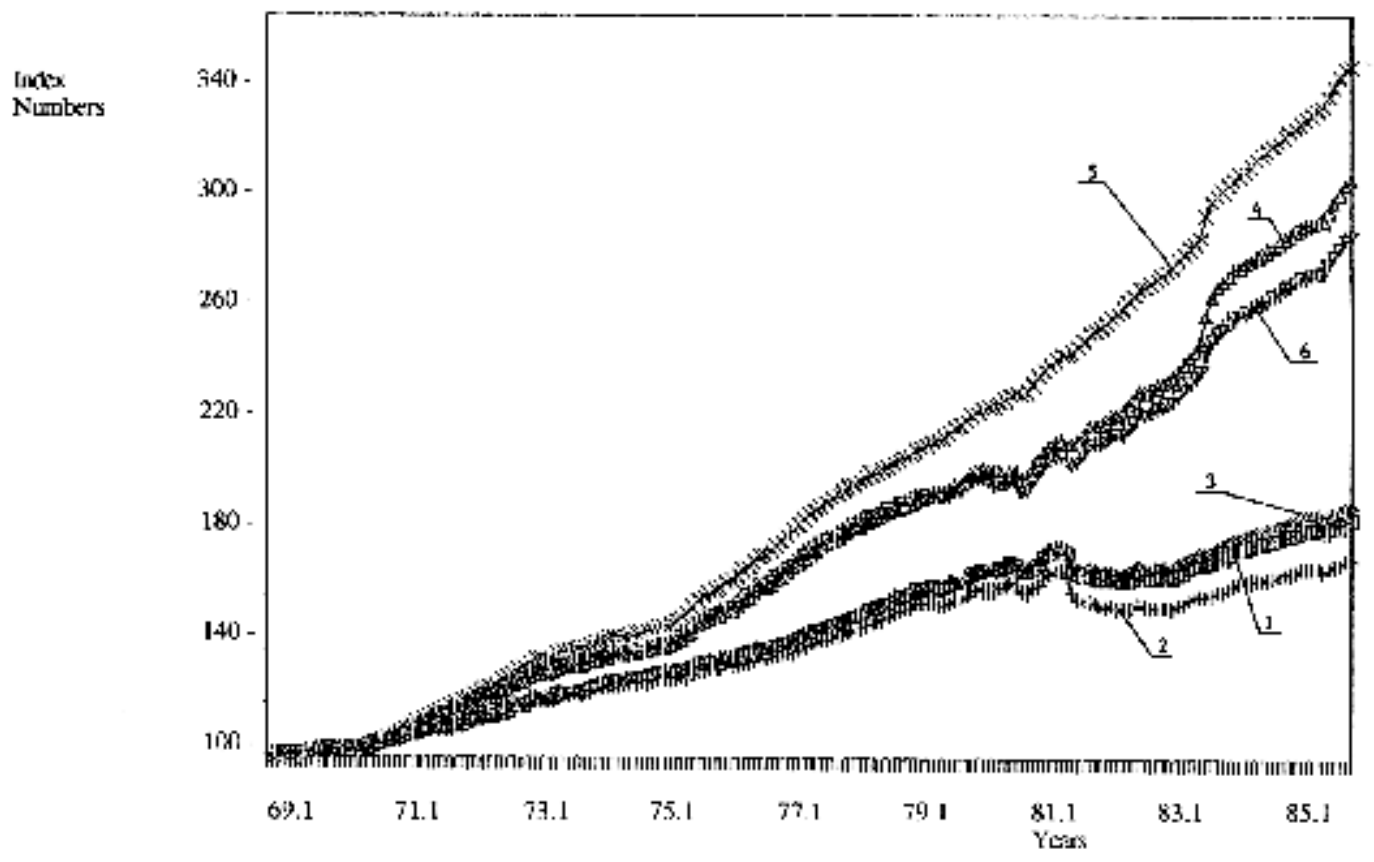

Fígure 1: Levels of nominal per capita M1 and M2 monetary indices (1, M1 theoretic; 2, M1 simple sum; 3, M1 Divisia; 4, Y2 theoretic; 5, M2 simple silm; 6, M2 Divisia). 
Figure 2: Estimated normalized bispectrum level surfaces for real per capita Divisia M2

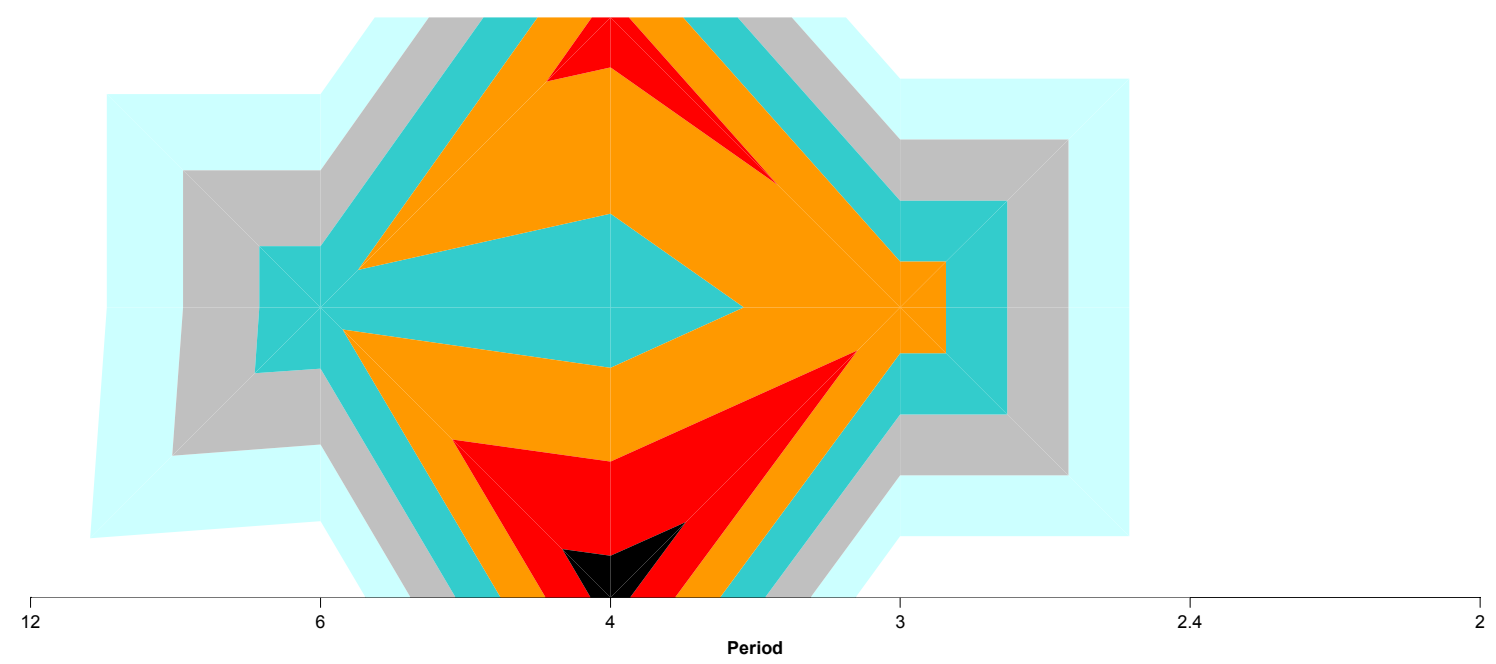


FOOTNOTES:

1. For a survey limited to the consumer demand side, see Barnett, Fisher, and Serletis (1992).

See Belongia (1996) and Belongia and Chalfant (1989) for some empirical results. For a

presentation of the theory in the perfect certainty case for consumers, manufacturing firms, and

financial intermediaries, see Barnett (1987). For international results on Divisia monetary

aggregation, see Belongia and Binner (2000).

${ }^{1}$ A nonzero probability must exist that the holding period return, $\mathrm{R}_{\mathrm{S}}$, on the benchmark asset will exceed that of any other asset during period s, since no other motivation for holding the benchmark asset exists within the consumer's decision problem, as defined below. In fact, since the variance of the distribution of $R_{S}$ is likely to be high relative to that of $r_{\text {is }}$ for any $i$, we should expect the mean of $R_{S}$ to exceed that of any element of $\mathbf{r}_{\mathrm{S}}$.

2. Although money may not exist in the elementary utility function, there exists a derived utility function that contains money, so long as money has positive value in equilibrium. See, e.g., Arrow and Hahn (1971), Phlips and Spinnewyn (1982), and Feenstra (1986). We implicitly are using that derived utility function.

${ }^{1}$ Assuming that $\mathrm{X}$ is linearly homogeneous, the exact price aggregator function is the unit cost function.

3. On testing for weak separability, also see Swofford and Whitney (1987).

4. Although component data is available for more recent months, we decided to use the data supplied in the appendix of Fayyad (1986) to assure comparability with Barnett, Hinich, and Yue (1991), who also published that data along with results which are worth comparing with those in this paper. But in our frequency domain analysis, we use that data only when comparison with 
Barnett, Hinich, and Yue (1991) is relevant. Otherwise we use updated data now maintained and published by the St. Louis Federal Reserve Bank. That data can be found in St. Louis Federal Reserve Bank's data web site, FRED. For links to that source of Divisia monetary aggregate data, as well as to international sources of Divisia monetary aggregate data, see: http://wuecon.wustl.edu/ barnett/.

5. See Barnett, William A., Melvin Hinich, and Piyu Yue (1991) regarding the need to test for weak separability and for further details regarding the data.

6. Formally, we assume that $\mathbf{x}_{\mathrm{S}}$ is in a weakly separable block within $\mathrm{u}$, with linearly homogeneous category utility function $X\left(\mathbf{x}_{\mathrm{S}}\right)$. The true cost of living index $\mathrm{p}_{\mathrm{s}}^{*}=\mathrm{p} *\left(\mathbf{p}_{\mathrm{S}}\right)$ is the unit cost function dual to the quantity aggregator function, $\mathrm{X}_{\mathrm{s}}$. As described earlier, we approximate the true cost of living index by the Fisher ideal index.

We are able to appeal to perfect certainty aggregation theory in this case, since current period prices, unlike current period interest rates, are known in the current period. Hence two stage budgeting over consumer goods is possible, and thereby perfect certainty aggregation and index number theory are applicable to consumer goods.

7. The strong separability assumption is largely for expository convenience. Weak separability of the form $\mathrm{u}\left(\mathbf{m}_{1 \mathrm{~s}}, \mathbf{m}_{2 \mathrm{~s}}, \mathrm{~L}_{\mathrm{s}}, \mathbf{x}_{\mathrm{s}}\right)=\mathrm{U}\left[\mathrm{V}\left(\mathrm{M}\left(\mathbf{m}_{1 \mathrm{~s}}\right), \mathrm{X}_{\mathrm{s}}\right), \mathbf{m}_{2 \mathrm{~s}}, \mathrm{~L}_{\mathrm{s}}\right]$ would be sufficient to assure the existence of the function $\mathrm{V}\left(\mathrm{M}\left(\mathbf{m}_{1 \mathrm{~s}}\right), \mathrm{X}_{\mathrm{s}}\right)$ that we use below.

8. We use the same aggregator function specifications used by Poterba and Rotemberg (1987), although we believe that at a later stage of this research the aggregator functions should be replaced by those of the highly flexible seminonparametric AIM (asymptotically ideal model) specification. See, e.g., Barnett, Geweke, and Wolfe (1991a,b) and Barnett, Geweke, and Yue(1991). 
9. The t-ratios should be interpreted with caution, since the use of transformations of parameters to impose inequality constraints biases conventional methods of estimating standard errors. As a result, we supply no standard errors or t-ratios for the original untransformed parameters. ${ }^{1}$ In particular, superNow accounts were introduced during January 1983 and money market deposit accounts were introduced during December 1982. The period during which the growth rate of the estimated Theoretic M2 aggregate diverged from the Divisia and simple sum M2 aggregates was September 1982 through April 1983.

10. Melvin Hinich, in personal correspondence, has suggested that the block-length be set to insure that $\ln (\mathrm{L}) / \ln (\mathrm{N}) \approx .4$. Consistency of the estimators requires that the parameter $\mathrm{e}=$ $\ln (\mathrm{L}) / \ln (\mathrm{N})<.5$.

11. If the last frame is incomplete, it is dropped from the calculation of the estimator.

12. For highly kurtotic stochastic processes, Hinich and Messer (1995) state that the use of the asymptotic distribution may not be warranted.

13. We employ a trapezoidal taper to reduce side lobe distortion. Some modification of these formulas is therefore required.

14. Koopmans (1974) called this tradeoff the Grenander uncertainty principle. For a discussion of power spectral estimation, see Kay and Marple (1981).

15. The axes are the periods of the two frequencies, varying from 12 down to 2 . The vertical axis (not displayed in the figure) is scaled identically to the horizontal axis, and also varies from 12 down to 2 as the vertical axis rises in the figure. The height of the estimated skewness function above the frequency pair plane is identified by the color code. 


\section{FOOTNOTES:}

${ }^{1}$ For a survey limited to the consumer demand side, see Barnett, Fisher, and Serletis (1992). See Belongia (1996) and Belongia and Chalfant (1989) for some empirical results. For a presentation of the theory in the perfect certainty case for consumers, manufacturing firms, and financial intermediaries, see Barnett (1987). For international results on Divisia monetary aggregation, see Belongia and Binner (2000).

${ }^{2}$ A nonzero probability must exist that the holding period return, $R_{\mathrm{S}}$, on the benchmark asset will exceed that of any other asset during period s, since no other motivation for holding the benchmark asset exists within the consumer's decision problem, as defined below. In fact, since the variance of the distribution of $R_{S}$ is likely to be high relative to that of $r_{\text {is }}$ for any $i$, we should expect the mean of $R_{S}$ to exceed that of any element of $\mathbf{r}_{\mathrm{S}}$.

${ }^{3}$ Although money may not exist in the elementary utility function, there exists a derived utility function that contains money, so long as money has positive value in equilibrium. See, e.g., Arrow and Hahn (1971), Phlips and Spinnewyn (1982), and Feenstra (1986). We implicitly are using that derived utility function.

${ }^{4}$ Assuming that $\mathrm{X}$ is linearly homogeneous, the exact price aggregator function is the unit cost function.

${ }^{5}$ On testing for weak separability, also see Swofford and Whitney (1987).

${ }^{6}$ Although component data is available for more recent months, we decided to use the data supplied in the appendix of Fayyad (1986) to assure comparability with Barnett, Hinich, and Yue (1991), who also published that data along with results which are worth comparing with those in 
this paper. But in our frequency domain analysis, we use that data only when comparison with Barnett, Hinich, and Yue (1991) is relevant. Otherwise we use updated data now maintained and published by the St. Louis Federal Reserve Bank. That data can be found in St. Louis Federal Reserve Bank's data web site, FRED. For links to that source of Divisia monetary aggregate data, as well as to international sources of Divisia monetary aggregate data, see: http://wuecon.wustl.edu/ barnett/.

${ }^{7}$ See Barnett, William A., Melvin Hinich, and Piyu Yue (1991) regarding the need to test for weak separability and for further details regarding the data.

${ }^{8}$ Formally, we assume that $\mathbf{x}_{\mathrm{S}}$ is in a weakly separable block within $\mathrm{u}$, with linearly homogeneous category utility function $\mathrm{X}\left(\mathbf{x}_{\mathrm{S}}\right)$. The true cost of living index $\mathrm{p}_{\mathrm{s}}^{*}=\mathrm{p}^{*}\left(\mathbf{p}_{\mathrm{s}}\right)$ is the unit cost function dual to the quantity aggregator function, $\mathrm{X}_{\mathrm{s}}$. As described earlier, we approximate the true cost of living index by the Fisher ideal index.

We are able to appeal to perfect certainty aggregation theory in this case, since current period prices, unlike current period interest rates, are known in the current period. Hence two stage budgeting over consumer goods is possible, and thereby perfect certainty aggregation and index number theory are applicable to consumer goods.

${ }^{9}$ The strong separability assumption is largely for expository convenience. Weak separability of the form $\mathrm{u}\left(\mathbf{m}_{1 \mathrm{~s}}, \mathbf{m}_{2 \mathrm{~s}}, \mathrm{~L}_{\mathrm{s}}, \mathbf{x}_{\mathrm{s}}\right)=\mathrm{U}\left[\mathrm{V}\left(\mathrm{M}\left(\mathbf{m}_{1 \mathrm{~s}}\right), \mathrm{X}_{\mathrm{s}}\right), \mathbf{m}_{2 \mathrm{~s}}, \mathrm{~L}_{\mathrm{s}}\right]$ would be sufficient to assure the existence of the function $\mathrm{V}\left(\mathrm{M}\left(\mathbf{m}_{1 \mathrm{~s}}\right), \mathrm{X}_{\mathrm{s}}\right)$ that we use below.

${ }^{10} \mathrm{We}$ use the same aggregator function specifications used by Poterba and Rotemberg (1987), although we believe that at a later stage of this research the aggregator functions should be replaced by those of the highly flexible seminonparametric AIM (asymptotically ideal model) 
specification. See, e.g., Barnett, Geweke, and Wolfe (1991a,b) and Barnett, Geweke, and Yue(1991).

${ }^{11}$ The t-ratios should be interpreted with caution, since the use of transformations of parameters to impose inequality constraints biases conventional methods of estimating standard errors. As a result, we supply no standard errors or t-ratios for the original untransformed parameters. ${ }^{12}$ In particular, superNow accounts were introduced during January 1983 and money market deposit accounts were introduced during December 1982. The period during which the growth rate of the estimated Theoretic M2 aggregate diverged from the Divisia and simple sum M2 aggregates was September 1982 through April 1983.

${ }^{13}$ Melvin Hinich, in personal correspondence, has suggested that the block-length be set to insure that $\ln (\mathrm{L}) / \ln (\mathrm{N}) \approx .4$. Consistency of the estimators requires that the parameter $\mathrm{e}=\ln (\mathrm{L}) / \ln (\mathrm{N})<$ .5.

${ }^{14}$ If the last frame is incomplete, it is dropped from the calculation of the estimator.

${ }^{15}$ For highly kurtotic stochastic processes, Hinich and Messer (1995) state that the use of the asymptotic distribution may not be warranted.

${ }^{16}$ We employ a trapezoidal taper to reduce side lobe distortion. Some modification of these formulas is therefore required.

${ }^{17}$ Koopmans (1974) called this tradeoff the Grenander uncertainty principle. For a discussion of power spectral estimation, see Kay and Marple (1981).

${ }^{18}$ The axes are the periods of the two frequencies, varying from 12 down to 2 . The vertical axis (not displayed in the figure) is scaled identically to the horizontal axis, and also varies from 12 
down to 2 as the vertical axis rises in the figure. The height of the estimated skewness function above the frequency pair plane is identified by the color code. 